\title{
Die IDS-Goethe-Studie in den Integrationskursen: Kollektive Sprachbiografien, erkennbare Teilnehmergruppen und sprachliche Selbsteinschätzungen ${ }^{1}$
}

\begin{abstract}
Der Beitrag widmet sich den Geflüchteten als Teil der deutschlernenden Teilnehmer/innen in den staatlich verordneten Integrationskursen (IKs). Unsere Erhebung unter 305 Geflüchteten aus Syrien und anderen Ländern legt ihren Schwerpunkt auf die sprachlichen Hintergründe. Dabei werden soziodemografische Daten mit Angaben zum Spracherwerb in Beziehung gesetzt und als kollektive Sprachbiografien dargestellt. Des Weiteren beschreiben wir sieben Teilnehmergruppen von Geflüchteten in den IKs, die sich vor allem auf Grund der Faktoren Alter, Bildungsgrad und Arbeitserfahrung unterscheiden, für die aber auch Merkmale im Hinblick auf Herkunft und Mehrsprachigkeit eine Rolle spielen. Ferner werden Angaben zur Sozialsituation in Deutschland mit Einschätzungen zum Deutscherwerb in Beziehung gesetzt. Ein Vergleich mit anderen Studien verdeutlicht die Verschiebungen in der Zusammensetzung des IK. Unser Beitrag kann als Anregung verstanden werden, die Passgenauigkeit im Sinne der Deutschlernenden zu überdenken.

This article focusses on the linguistic backgrounds of refugees currently learning German in state mandated integration courses. It is based on a survey of 305 refugees from Syria and other countries. We generate collective language biographies based on sociodemographic data and information on language acquisition. Furthermore, we describe seven groups of participants which can be distinguished on the basis of age, education and work experience. The members also share traits with regard to origin and the role of multilingualism. We also correlate data on refugees' social situation with their self-assessment in German. We conclude by drawing a comparison to other studies and underlining the shift in the composition of integration courses. Our analysis offers an impulse to reconsider how these courses should be composed to best serve those acquiring German.
\end{abstract}

\section{Einführung}

Keine Bildungssituation in Deutschland verkörpert derzeit den gesellschaftlichen Eingliederungsprozess von Flüchtlingen und anderen Einwanderergruppen so sehr wie der Integrationskurs (IK). Nach zahlreichen integrationspolitischen Veränderungen der vergangenen 20 Jahre steht der IK allen alphabetisierten Zugewanderten grundsätzlich offen, wird durch das Bundesamt für Migration und Flüchtlinge (BAMF) zentral koordiniert und ist bundesweit verbreitet. Die Kosten werden für die meisten Teilnehmer/innen übernommen oder erstattet. Hier erwerben Menschen verschiedenster Herkunft und unterschiedlichster Hintergründe erste sprachliche Kompetenzen des Deutschen, die am Ende des Kurses mit Anspruch auf Vergleichbarkeit geprüft werden. Ziel ist das Referenzniveau B 1 des gemeinsamen europäischen Referenzrahmens (GER), das besagt, dass sich Teilnehmer/innen im Alltag zurechtfinden und sprachliche Selbstständigkeit erwerben. Der Integrationskurs steht darüber hinaus oft symbolisch für den aktiven Umgang mit Migration und den damit verbundenen Begriff der "Willkommenskultur“, während seine Existenz gleichzeitig gewisse Integrationsforderungen gegenüber Neuzuwanderern bekräftigt. Nicht zuletzt

Ohne die logistische Durchführung der Erhebung und die Aufbereitung der Daten hätte keine Analyse stattfinden können. Wir danken allen Mitarbeiter/innen des IDS, des Goethe-Instituts Mannheim und der Firma Froschgift, die an diesem Prozess beteiligt waren. Insbesondere die Kollegen Ibrahim Cindark und Marc Oberle sind an dieser Stelle hervorzuheben. 
auf Grund seines Namens hinterlässt der IK in der öffentlichen Wahrnehmung den Eindruck eines Eingangstores in die Gesellschaft - wozu auch das Berufsleben zählt. Jeder empirische Blick auf den Integrationskurs ist damit zugleich ein Blick auf die praktische Umsetzung und Umsetzbarkeit integrationspolitischer Forderungen und Vorstellungen in Zeiten relativ hohen Migrationsdrucks.

Wohl aus diesem Grunde legten bisherige Integrationskursstudien ihren Schwerpunkt eher auf die Frage, ob die Effizienz des Kurses seinem Namen Rechnung trägt (vgl. Haug/ Zerger 2006; Schuller/Lochner/Rother 2011; Schroeder/Zakharova 2015; Scheible/Rother 2017). Wer in den Kursen sitzt und welche Hintergründe die Menschen in diese gerahmte Integrationssituation mitbringen, wurde dabei wenig beleuchtet. Das Projekt „Deutsch im Beruf" befasst sich im vorliegenden Beitrag mit den sprachlich-soziodemografischen Hintergründen der Teilnehmer/innen. Denn die Ereignisse des Sommers 2015 haben die ohnehin komplexen Kurszusammensetzungen drastisch verändert. Neben einer starken Zunahme von Geflüchteten aus Syrien gibt es auch andere Teilnehmer/innen in den Kursen, die auf eine Fluchtmigration zurückblicken. Oft sind die Zusammenhänge zwischen Herkunft, sozialen Hintergründen, Spracherwerbsbiografien, Sprachrepertoires, Fluchterfahrung und Sprachkontakt nur grob bekannt. In diesem Artikel widmen wir uns einer Reihe wichtiger Fragen, die sich aus dieser Situation ergeben:

- Welche Herkunftsgruppen lassen sich identifizieren? Sind diese Gruppen mehrsprachig?

- Welche Erstsprachen dominieren, welche Minderheitensprachen gibt es und welche Fremdsprachen haben die Geflüchteten erworben? Und wie hängt dies mit Ethnien, Bildungskarrieren, Arbeitserfahrung und Fluchtverläufen zusammen?

- Welche Gemeinsamkeiten und Unterschiede gibt es in den Sprachbiografien der Menschen unterschiedlicher Herkunft?

- Wie schätzen die Menschen selbst ihre Sprachkompetenzen ein?

- Auf welche Lernergruppen muss sich der Integrationsbetrieb zukünftig einstellen?

- Wie wirken sich Erwartungen an Deutschland und Kontakte mit Deutschen auf den Spracherwerb aus?

Zur Beantwortung dieser Fragen haben das Institut für Deutsche Sprache und das GoetheInstitut Mannheim im Herbst 2016 in 42 allgemeinen Integrationskursen ${ }^{2}$ Umfragen mit $^{-}$ 305 Teilnehmer/innen mit Fluchterfahrung durchgeführt.

Unser Beitrag gliedert sich wie folgt: Abschnitt 2 gibt einen Überblick über die Forschungssituation, wobei wir zunächst auf die Migrationslinguistik eingehen, die sich seit Jahrzehnten thematisch und methodisch mit sprachlicher Integration, Mehrsprachigkeit und sprachbiografischen Darstellungen befasst. In Abschnitt 2.2 stehen Studien zum IK und zu Geflüchteten unter Beteiligung des Bundesamtes für Migration und Flüchtlinge (BAMF) im Vordergrund. Abschnitt 3 stellt Methode und Design unserer Erhebung vor. Die Durchführung und einige Schwierigkeiten, die unserem Team im Feld begegneten, werden in Abschnitt 4 beschrieben. Die Präsentation der wichtigsten Ergebnisse in Abschnitt 5 gliedert sich nach vier Aspekten. Zuerst werden in 5.1 grundlegende Sozial-

Integrationskurse werden vom Bundesamt für Migration und Flüchtlinge als „allgemein“ bezeichnet, wenn sie sich nicht an eine spezielle Zielgruppe mit besonderen Lernbedürfnissen (z.B. Eltern, Jugendliche, Analphabeten etc.) richten. 
daten für alle Geflüchteten präsentiert. In 5.2 visualisieren wir kollektive Sprachbiografien und diskutieren Zusammenhänge zwischen Sozialdaten und Sprachangaben vor allem für die Herkunftsgruppe aus Syrien, aber auch für die eritreischen und iranischen Geflüchteten. In 5.3 wird das Ergebnis einer Clusteranalyse präsentiert, die Unterschiede innerhalb der Kursteilnehmergruppe mit Fluchthintergrund hervorhebt und somit für eine zielgruppengerechte Ausrichtung der Kurse relevant ist. In 5.4 werfen wir schließlich einen Blick auf die soziale und sprachliche Situation der Geflüchteten in Deutschland. Dabei werden auch Daten der zweiten Erhebungswelle berücksichtigt, die Hinweise auf eine längsschnittliche Entwicklung von Sozialkontakten und die Auswirkung auf den Deutscherwerb geben. Im siebten Abschnitt vergleichen wir unsere Ergebnisse mit den Ergebnissen bisheriger Studien. Eine Zusammenfassung der Ergebnisse rundet unseren Beitrag ab.

\section{Forschungssituation}

2.1 Mehrsprachigkeit, Sprachbiografien und Deutscherwerb in der Migrationslinguistik

Die sprachlichen Begleiterscheinungen der Nachkriegsmigration sind in Deutschland seit rund 60 Jahren Gegenstand systematischer Forschung. ${ }^{3}$ Die Veränderung der Migrationsmuster und der Wandel der Einwanderungspolitik haben die Schwerpunktsetzung der Migrationslinguistik inhaltlich und methodisch stark beeinflusst. Wie viel und welche Art von Aufmerksamkeit dem Thema „Mehrsprachigkeit“ und den „Sprachbiografien“ der Zugewanderten gewidmet wurde, hing zum Beispiel maßgeblich mit der Population zusammen, für die eine Forderung nach „Integration“ formuliert wurde. Ende der 1960er Jahre bis Ende der 1980er standen die Gastarbeiter/innen aus dem südeuropäischen Ausland und der Türkei mit ihren Familien im Fokus. In dieser ersten Phase galt das linguistische Forschungsinteresse dem ungesteuerten Zweitspracherwerb und der möglichen Entstehung von nichtstandardsprachlichen Varietäten des Deutschen unter Erwachsenen (Heidelberger Forschungsgruppe Pidgin (Hg.) 1975; Klein/Dittmar 1979; OrlovićSchwarzwald 1978; Keim 1978; Clahsen/Meisel/Pienemann 1983). Auch der gesteuerte Erwerb der Zweitsprache Deutsch in sogenannten Ausländerklassen wurde dokumentiert, analysiert und kritisiert (Meyer-Ingwersen/Neumann/Kummer 1977; Stölting 1980; Pfaff 1984). In den Untersuchungen kamen meist quantitative Methoden (Faktoranalysen, Fehleranalysen u.a.) zum Einsatz, und es häuften sich Hinweise auf die Einbettung in das deutschsprachige Umfeld als wichtigen Faktor für einen standardnahen Deutscherwerb.

Bis Mitte der 1990er Jahre veränderte sich die Zuwanderung auf Grund neuer politischer Rahmenbedingungen. Im Zuge der Auflösung der Sowjetunion, der Öffnung des Schengen-Raums und zunehmend globalisierter Arbeitsmärkte stiegen die Asylmigration, die innereuropäische Mobilität und etwas später auch der Zuzug von Fachkräften aus dem Ausland (Herbert 2001; Wiater/Videsott 2009). Der Begriff der „Superdiversität“ beschreibt das Ergebnis dieser Entwicklungen nach der Jahrtausendwende aus soziologischer Sicht (Vertovec 2007): Im Prozess der Diversifizierung der bis dahin vorherrschen-

3 Die Integration der deutschen Vertriebenen nach dem Zweiten Weltkrieg wird hier ausgespart, weil Mehrsprachigkeit hier eine untergeordnete Rolle spielt. Zur dialektalen Akkommodation durch die Heimatvertriebenen siehe Ehlers $(2013,2015)$. 
den Migrationsmuster lösten sich auch die gedachten Verbindungen zwischen Nationalität, Ethnizität, Religion und sozialem Status schrittweise auf. Forderungen nach einer "Soziolinguistik der Globalisierung“ (Blommaert 2010), die diesen Entwicklungen gerecht wird, wurden zu einem Zeitpunkt formuliert als die Migrationslinguistik in Deutschland sich bereits stark gewandelt hatte: Ins Zentrum des Interesses war die zweite Generation gerückt, also die Kinder und Jugendlichen mit Migrationshintergrund, die in Deutschland geboren oder zumindest aufgewachsen waren. Mit ihnen wurde Mehrsprachigkeit im Bildungswesen (Gogolin 1994), im Hinblick auf die sprachliche Entwicklung (Meisel 2007) und auf die gesellschaftliche Gesamtsituation (Eichinger/Plewnia/ Steinle (Hg.) 2011) zu einem zentralen Thema. Auch das Interesse an Code-Switching und der Entstehung hybrider Sprechweisen stieg mit der neuen Generation an (Auer 1999; Dirim/Auer 2004; Hinnenkamp 2005; Cindark 2013). Für starkes politisches Interesse sorgte auch die Debatte um die Entstehung sogenannter (Multi-)Ethnolekte, also eigener migrantischer Formen des Deutschen (Füglein 2000; Clyne 2000; Wiese 2009, 2012; Auer 2013). In den genannten Forschungsgebieten entwickelten sich vor allem qualitative Methoden: Am IDS trat die Ethnografie des Sprechens nach Hymes (1962) und Gumperz/Hymes (Hg.) (1972) in enge Verbindung mit der Konversationsanalyse (Deppermann 2000, 2005; Keim 2007; Cindark 2010). Ethnografisches Arbeiten im Sprecherumfeld nimmt auch in der Forschung zur „Superdiversität“ eine zentrale Stellung ein (vgl. Blommaert 2013). Das Repertoire erweiterte sich zusätzlich um die Dokumentation und Untersuchung individueller, narrativer Sprachbiografien (Franceschini 2002; Fix 2010; Thüne/Betten (Hg.) 2011) und Sprachenportraits (Krumm 2001; Busch 2010). Inwiefern erzählte sprachbiografische Erfahrungen jedoch wirklich erlebte Sprachbiografien widerspiegeln, war von Anfang an umstritten (Tophinke 2002).

Interessanterweise entwickelte sich parallel zu den neuen Forschungsschwerpunkten und -methoden in der Migrationslinguistik kein quantitativer Ansatz mit dem Ziel, einen Überblick über die Gesamtsituation der Mehrsprachigkeit und über kollektive Sprachbiografien zu geben. Eine solche Vogelschau auf das Gesamtgeschehen wäre vor allem vor dem Hintergrund des Migrations- und Integrationsmanagements interessant, das auf lokaler und nationaler Ebene stattfindet. Eine Kritik an der mangelhaften kartografischen Erfassung von Sprachvorkommen in deutschen Städten übt zum Beispiel Stevenson (2013). Das sogenannte „Linguistic Landscaping“ stellt einen Versuch dar, Mehrsprachigkeit durch die Dokumentation von sichtbaren, schriftlichen Vorkommen in Wohnbezirken einiger Städte zu quantifizieren (vgl. Cindark/Ziegler 2016), womit zumindest grundlegende Rückschlüsse auf die Sprachsituation möglich sind. Allerdings stößt es im Hinblick auf Fragen nach gesprochener Sprache und der Sprachkompetenz an seine Grenzen. Die systematische Erhebung von Sprachvorkommen an Schulen (vgl. Fürstenau/Gogolin/Yağmur 2003; Chlosta/Ostermann 2005) steht vor ähnlichen Problemen. Brizić (2007) verweist mit ihrem Sprachkapitalmodell auf die Rolle „verschwiegener Sprachen", die auch auf den Schulbetrieb im Einwanderungsland wirken. So ist eine Sensibilisierung für die sprachpolitische Situation der Herkunftsländer unabdingbar, um die Bildungssituation neuer Herkunftsgruppen in Europa einordnen zu können und den Ursprung von Kompetenzrückständen erklären zu können. In die Reihe dieser Studien, die die aktuelle Lage im Hinblick auf Mehrsprachigkeit besser beleuchten sollen, stellt sich die IDS-Goethe-Studie, die sich den Geflüchteten mit Bleibeperspektive widmet, die in den Integrationskursen zu finden sind und die wie andere Einwanderergruppen zuvor, in Deutschland Fuß fassen werden. 
Vereinfachend lässt sich die Entwicklung der Einwanderung und des Deutscherwerbs wie folgt beschreiben (siehe Tab. 1). Die relativ beschränkten Zuwanderungsbedingungen zur Zeit der Gastarbeiteranwerbung gingen mit einem ungesteuerten Erwerb des Deutschen einher. In dieser Phase war es vergleichsweise einfach, einen guten Überblick über die Sprachen und Sprechergruppen zu behalten. Als sich die Zuwanderungsbedingungen nach 1990 liberalisierten, verlief der Erwerb des Deutschen für die meisten erwachsenen Zuwanderer weiterhin ungesteuert. Sprachen und Sprechergruppen wurden in dieser Phase unübersichtlicher. Erst nach der Jahrtausendwende wurden systematisch Daten zur Klärung der Situation erhoben.

\begin{tabular}{|l|l|l|}
\hline \multicolumn{1}{|c|}{ Zuwanderung: } & $\begin{array}{l}\text { Grenzkontrollen, enge gesetzliche } \\
\text { Beschränkungen: }\end{array}$ & $\begin{array}{l}\text { Durchlässigere Grenzen (Schengen), } \\
\text { liberalisierte Gesetzeslage: }\end{array}$ \\
\hline Deutscherwerb: & $\begin{array}{l}\text { Ca. 1960-1985: Gastarbeiteranwer- } \\
\text { bung, Anwerbestopp, Familiennach- } \\
\text { zug, Kinder in ,Ausländerklassen“, } \\
\text { relativ überschaubare Sprachgruppen }\end{array}$ & $\begin{array}{l}\text { Ca. 1985-2005: zunehmende Asyl- } \\
\text { migration, Offnung des Schengen- } \\
\text { Raumes, Spätaussiedlerzuzug, hohe } \\
\text { sprachliche Komplexität }\end{array}$ \\
\hline Gesteuerter Erwerb & $\begin{array}{l}\text { Absehbare Zukunft: Sprachliche } \\
\text { Steuerung, Bemühung um mehr } \\
\text { Beschränkungen bei der Einwande- } \\
\text { rung }\end{array}$ & $\begin{array}{l}\text { Ca. 2005-2015: Einführung des Inte- } \\
\text { grationskurses im Rahmen des Zuwan- } \\
\text { derungsgesetzes, Aufnahme von } \\
\text { Flüchtlingen im Sommer 2015, noch } \\
\text { größere sprachliche Heterogenität }\end{array}$ \\
\hline
\end{tabular}

Tab. 1: Phasen der Zuwanderung und der politischen Antwort im Hinblick auf den Deutscherwerb

Mit Einführung der verpflichtenden Integrationskurse ändert sich die Situation im Hinblick auf den Deutscherwerb grundlegend: Auch erwachsene (und jugendliche) Zuwanderer erhalten nun flächendeckend Sprachunterricht. Mit der Fluchtsituation 2015 verschiebt sich die Teilnehmerpopulation der Kurse und wird insgesamt noch heterogener als in den Jahren zuvor (auch wenn sich lokal die hohe Anzahl an Asylsuchenden homogenisierend auswirken kann). Eine weitere Phase in der Beziehung zwischen Spracherwerb und Einwanderungspolitik zeichnet sich indes ab: Der Ruf nach einer restriktiveren oder klarer geregelten Gesetzeslage wird (nicht nur in Deutschland) lauter. Die Bemühung um sprachliche „Integration“ durch verordnete Kurse könnte zukünftig stärker an die politische Kontrolle über Einwanderung gekoppelt sein. Ob diese Koppelung im Sinne einer „Willkommenskultur" oder einer Eindämmung von Migration gestaltet wird, werden die kommenden Jahre zeigen.

\subsection{Studien zu Integrationskursen und Geflüchteten}

\subsubsection{Grundlegendes zum Integrationskurs}

Der im Zuge des Zuwanderungsgesetzes im Jahre 2005 bundesweit eingeführte Integrationskurs besteht aus einem Sprachkurs von 600 Unterrichtseinheiten à 45 Minuten und einem gesellschaftskundlichen Orientierungskurs von weiteren 100 Unterrichtseinheiten (vormals 30 Unterrichtseinheiten). Der neue Kurs verfolgte von Beginn an das Ziel, ,ausreichende Kenntnisse“ ${ }^{4}$ der deutschen Sprache sowie Kenntnisse zu Alltag,

4 Über ,,ausreichende Sprachkenntnisse“ verfügt laut der Verordnung über die Durchführung von Integrationskursen $(\$ 3(2))$, wer „,sich im täglichen Leben in seiner Umgebung selbständig sprachlich 
Rechtsordnung, Kultur und Geschichte des Landes zu vermitteln. Zur Teilnahme am gesamten Kurs sind Zugewanderte verpflichtet, die „sich nicht auf einfache Art in deutscher Sprache mündlich verständigen können bzw. die noch nicht über ausreichende Kenntnisse der deutschen Sprache verfügen" (Bundesamt für Migration und Flüchtlinge (Hg.) 2017) sowie Ausländer/innen mit besonderem Integrationsbedarf und solche, die nach SGB II und seit 2017 nach dem Asylbewerberleistungsgesetz Leistungen beziehen. Letztere können von den Trägern der jeweiligen Leistungen zur Teilnahme verpflichtet werden. Zur Teilnahme berechtigt sind zudem Bürger/innen der europäischen Union, Personen die als „Spätaussiedler“ geführt werden und Personen, die nach dem Asylbewerberleistungsgesetz Leistungen beziehen, nicht verpflichtet wurden, aber eine Bleibeperspektive oder Aufenthaltserlaubnis besitzen. Um den individuellen Situationen der vielfältigen Zielgruppen entgegenzukommen und die Durchführung der Kurse zu erleichtern, wurden mehrere Arten von Kursen entwickelt. Derzeit gibt es neben dem allgemeinen Integrationskurs auch spezielle Kursangebote für Jugendliche, Frauen, Eltern, Analphabeten und Zweitschriftlernende. Zudem durchlaufen alle Teilnehmer/innen vor Beginn des Kurses einen Einstufungstest und werden dann einem Modul zugeordnet. Die ersten drei Sprachmodule des Kurses à 100 Unterrichtseinheiten werden als „Basismodule“ bezeichnet. Der Aufbausprachkurs besteht aus drei weiteren Modulen à 100 Unterrichtseinheiten. Er endet mit dem Abschlusstest „Deutschtest für Zuwanderer“ (DTZ). Der Orientierungskurs und der dazugehörige Abschlusstest „Leben in Deutschland“ (LiD) schließen den Integrationskurs ab. Wer DTZ und LiD erfolgreich besteht, erhält das „Zertifikat Integrationskurs“.

\subsubsection{Studien des BAMF im Integrationskurs}

Der Integrationskurs unterliegt regelmäßigen Qualitätskontrollen. Auf zwei Studien, die wir mit unseren Ergebnissen kontrastieren werden, soll hier kurz eingegangen werden.

Mit dem Ziel, den Bedarf an zielgruppenorientierten Integrationskursen zu eruieren, führten Haug/Zerger (2006) im Auftrag des BAMF bald nach Einführung der Kurse im Jahr 2005 eine bundesweite Befragung mit 1.304 Teilnehmer/innen aus 86 allgemeinen Integrationskursen durch, bei der neben soziodemografischen Daten auch Fragen zum Kurs und zu Änderungswünschen gestellt wurden. Das Durchschnittsalter lag bei 34,2 Jahren, wobei etwas mehr Frauen an den Kursen teilnahmen als Männer (55\% vs. 45\%). Zum Zeitpunkt der Befragung bestand der Teilnehmerpool zur Hälfte aus neu zugewanderten Personen aus den Jahren 2005 und 2004. Darunter befanden sich sehr viele Spätaussiedler/innen (über 55\%). Nur 5\% der Teilnehmer/innen stammten aus der EU. 36,7\% der Neuzugewanderten gaben an, bei der Ankunft in Deutschland über Deutschkenntnisse verfügt zu haben. Viele der Spätaussiedler/innen und EU-Ausländer/innen verfügten über einen Schulabschluss (über 85\%), bei Zugewanderten aus anderen Ländern lag die Quote bei unter 70\%. Insgesamt hatten über $80 \%$ der Kursteilnehmer/innen im Herkunftsland bereits gearbeitet. Entsprechend häufig wurde eine „sehr ausführliche“ Behandlung der Themen „Arbeitsplatzsuche“ (22\%), „Schule und Ausbildungssystem“ (19\%) und „Ausbildungsplatzsuche und Bewerbung" (16\%) gewünscht. Auf die Frage nach den Plänen nach dem Kurs antworteten die meisten Teilnehmenden ,weitere Sprachkenntnisse erwerben“ (78\%), ,einen Aus-

zurechtfinden und entsprechend seinem Alter und Bildungsstand ein Gespräch führen und sich schriftlich ausdrücken kann (Niveau B 1 des Gemeinsamen Europäischen Referenzrahmens für Sprachen). " Unklar ist, ob mit diesem Sprachniveau auch eine berufliche Betätigung aufgenommen werden soll. 
bildungs-/Arbeitsplatz finden“ (77\%) und „Kontakte zu Deutschen finden“ (77\%). Die Ergebnisse dieser Umfrage führten zu Ausdifferenzierungen im Kursangebot des BAMF (Frauenkurse, Jugendkurse etc.).

Im Jahr 2007 konzipierte das BAMF das „Integrationspanel“ mit dem Ziel, den Integrationsverlauf von Integrationskursteilnehmer/innen besser verfolgen zu können (Schuller/ Lochner/Rother 2011). In einer ersten Welle im Jahr 2007 wurden die soziodemografischen Daten von ca. 4.000 Kursteilnehmer/innen und einer Kontrollgruppe von ca. 3.700 Zuwanderern erhoben, die nicht im Integrationskurs Deutsch erwarben. Die zur Erhebung der Daten eingesetzten Fragebögen wurden auf Deutsch verfasst und zur Orientierung in die 13 häufigsten Muttersprachen der Kursteilteilnehmer/innen übersetzt. ${ }^{5}$ Anhand von 2.097 Rückläufen aus 253 Kursen ergab sich in der ersten Erhebungswelle folgendes Bild: Eine Minderheit war im Jahr 2007 unter 30 Jahre alt (37\%), das Durchschnittsalter lag bei 35 Jahren. Mit 63\% war die Mehrheit der Teilnehmenden weiblich. Die durchschnittliche Aufenthaltsdauer in Deutschland lag bei 5,2 Jahren, wobei 56\% vor Kurzem zugewandert war. Die Herkunft war wesentlich heterogener als noch zwei Jahre zuvor: $18 \%$ kamen aus Russland, $17 \%$ aus der Türkei und 16\% aus den GUS-Staaten (ohne Russland). Damit waren Spätaussiedler/innen nur noch mit höchstens 34\% vertreten. 41\% der Teilnehmenden stammten aus Drittstaaten in Asien, Afrika und Südosteuropa und 8\% kamen aus der EU. Einen Schulabschluss hatten $84 \%$ der Befragten, $46 \%$ sogar eine Hochschulzugangsberechtigung. $71 \%$ besaßen Berufserfahrung. Die Entwicklung der Deutschkenntnisse wurde über eine Selbsteinschätzung in den fünf Sprachfertigkeiten „Hören“, „Lesen“, „an Gesprächen teilnehmen“, „zusammenhängendes Sprechen“ und „Schreiben“ erfasst. Sie wurde mit anderen Integrationsindikatoren in Beziehung gesetzt (zum Beispiel der Häufigkeit deutscher Kontakte, Teilnahme am Arbeitsmarkt, Verbundenheit mit Deutschland etc.). Integrationsverläufe wurden außerdem nach Gruppenzugehörigkeiten untersucht (z.B. Herkunftsländer, Sprachgruppen, Teilnehmende aus Mischehen etc.). Die Ergebnisse wurden von den Autoren dahingehend interpretiert, dass der IK beim Spracherwerb und auch für die anderen Faktoren positive Wirkung im Gegensatz zur Kontrollgruppe entfaltet. Wie bei Haug/Zerger (2006) wurden auch Einstellungen der Kursteilnehmer/innen zum Kurs sowie Änderungswünsche erfasst.

Kritik am Integrationspanel üben vor allem Schroeder/Zakharova (2015). Sie merken an, dass Selbsteinschätzungen bei zunehmendem Sprachgefühl kritischer ausfallen und sich durch längsschnittlich erhobene Selbsteinschätzungen nicht auf das Ausmaß von Spracherwerbsfortschritten schließen lässt. Auch für die IDS-Goethe-Studie ist dieser Aspekt von Belang.

\subsubsection{Repräsentative IAB-BAMF-SOEP-Studie unter Geflüchteten}

Nach dem Zuzug von 1.100.000 Flüchtlingen nach Deutschland in den Jahren 2015 und 2016 entstand der Bedarf nach einer repräsentativen Datenbasis bezüglich der Geflüchteten. Das Institut für Arbeitsmarkt und Berufsforschung (IAB), das Forschungszentrum des BAMF (BAMF-FZ) und das „Sozio-oekonomische Panel“ (SOEP) setzten dieses Vorhaben im Jahr 2016 gemeinsam um (Babka von Gostomski et al. 2016). In 450 Fragen wurden Fluchtursachen, Fluchtwege, Bildungs- und Erwerbsbiografien, Verdienste und Vermögen, Werte, Einstellungen, Persönlichkeitsmerkmale, Sprachkenntnisse, der fami-

2007 waren diese Sprachen Albanisch, Arabisch, Chinesisch, Englisch, Französisch, Kroatisch, Persisch, Polnisch, Russisch, Spanisch, Thailändisch, Türkisch und Vietnamesisch. 
liäre Kontext, die soziale Vernetzung, der Stand des Asylverfahrens, die Unterkunftssituation, die Nutzung integrations- und arbeitsmarktpolitischer Maßnahmen und andere Inhalte erfasst. 2.349 Interviews lagen 2016 zu einer ersten Auswertung vor. Damit handelt es sich um die international umfangreichste Erhebung von Merkmalen zur Analyse von Fluchtmigration und Integration. Die Interviews wurden in Privathaushalten, Gemeinschaftsunterkünften und Erstaufnahmeeinrichtungen „Face-to-Face“ von geschultem Personal durchgeführt. Die Fragebögen standen in sieben Sprachen je schriftlich und in einem Audioformat zur Verfügung, sodass die Schriftbarriere überwunden werden konnte. ${ }^{6}$ Bereits bei den grundlegenden soziodemografischen Angaben zeigen sich deutliche Unterschiede zur Integrationskurspopulation in den früheren Studien. In der IAB-BAMF-SOEP-Befragung waren 66\% der Teilnehmenden männlichen Geschlechts. Zudem waren 58\% unter 30 Jahre alt. Die Herkunft war sehr heterogen, ein deutlicher Schwerpunkt lag auf Regionen, in denen kriegerische Konflikte herrschen: Über die Hälfte der Teilnehmer/innen kam aus Syrien (41,5\%), Afghanistan (10\%) und dem Irak (8\%). Weitere kamen aus Eritrea/Somalia (7\%), Albanien/Serbien/Kosovo (6\%) sowie Iran/Pakistan (4,5\%). Von den Befragten gaben $18 \%$ an, über ,gute" bis „,sehr gute“ und 35\% über „,mittlere“ Deutschkenntnisse zu verfügen. Wie in den Integrationskursen hatten $73 \%$ der Befragten vor dem Zuzug nach Deutschland Berufserfahrungen gesammelt.

Vergleicht man die sozialdemografischen Eckdaten der Studien, zeichnet sich ab, wie sich die Integrationskurspopulation ab 2015 demografisch verändern könnte: Unter den Geflüchteten gab es mehr Männer, sie waren jünger und erst seit kürzerer Zeit in Deutschland. Detaillierte Einblicke zu den Sprachhintergründen und Sprachbiografien von Integrationskursteilnehmenden fehlen allerdings. Die IAB-BAMF-SOEP-Studie gibt ebenfalls wenig Aufschluss über sprachliche Hintergründe der Flüchtlinge in den IKs. Solche Daten könnten vor allem für die pädagogische Ausrichtung des Curriculums und für eine Anpassung der Kursstrukturen von Bedeutung sein. Diese Lücke will die IDS-Goethe-Studie füllen.

\section{Vorüberlegungen und Methode}

Die Konzeption der IDS-Goethe-Studie wurde von einer Reihe von Vorüberlegungen zur Struktur des Kurses, zur Durchführbarkeit auf Grund der sprachlichen Situation sowie zur besonderen Situation der Flüchtlinge geleitet. Die wichtigsten sechs Punkte sind:

1) Wie die meisten Integrationskursstudien und die IAB-BAMF-SOEP Befragung zuvor, sollte die IDS-Goethe-Studie zwei Erhebungszeitpunkte umfassen, um längsschnittliche Entwicklungen feststellen zu können. Die Daten wurden zu Beginn des IK (in den Modulen 1/2) und zum Ende des letzten Sprachmoduls (in Modul 6) erhoben.

2) Das Umfrageverfahren wurde zeitlich und logistisch optimiert. Es wurde eine App entwickelt, um sowohl die Umfrage als auch die Sprachaufnahme am Tablet mit Headset durchzuführen. So war es auch leicht möglich, die Umfrage in anderen Sprachen anzubieten (siehe Punkt 3). Zudem wurde immer nur eine Frage präsentiert. Irrelevante Fragen wurden automatisch übersprungen, sodass sich die Teilnehmer/ innen nicht selbst in der Logik des Fragebogens zurechtfinden mussten.

3) Da die Teilnehmer/innen bei Kursbeginn in anderen Sprachen mehr Kompetenzen haben als im Deutschen, muss eine belastbare Erhebung normalerweise in der Erstsprache oder einer anderen - besser als Deutsch beherrschten - Fremdsprache erho-

6 Die Sprachen waren Arabisch, Kurmandschi, Farsi, Urdu, Paschtu, Deutsch und Englisch. 
ben werden. Nach einer Überprüfung der ehemals häufigsten Sprachvorkommen im IK wurde die Umfrage in einem mehrstufigen Verfahren in 16 weitere Sprachen übersetzt. ${ }^{7}$ Nur sehr wenige Teilnehmer/innen beantworteten unsere Umfrage demnach auf Deutsch. Fast immer fand sich eine besser verständliche Erst- oder Fremdsprache.

4) Aufgrund des Wissensstandes zur Mehrsprachigkeit (Brizić 2007; Blommaert 2010) wurde nicht von monolingualen, sondern von mehrsprachigen Teilnehmenden ausgegangen. Entsprechend wurden die Befragten in allen sprachbezogenen Fragen gebeten, auch geringe Sprachkenntnisse in einer Fremdsprache anzugeben. So konnten für fast alle Fragestellungen multiple Angaben gemacht werden.

5) Viele Geflüchtete stehen in sensiblen Anerkennungsverfahren und sind daher besorgt, dass Daten gegen sie verwendet werden könnten. Neben einem Einführungsvideo, in dem der Datenschutz durch die Projektleiter zugesichert wurde, wurde auch schriftlich auf die Datenschutzrichtlinien des IDS hingewiesen. Die Umfrageteams der IDSGoethe-Studie waren mehrsprachig besetzt, um auf Sorgen und Fragen der Teilnehmer/innen eingehen zu können. Nach Möglichkeit wurden Geflüchtete als Mitarbeiter eingesetzt, um das Vertrauen der Teilnehmer/innen zu gewinnen.

Um einen Datensatz mit einer stark besetzten Gruppe von Geflüchteten zu erstellen, wurden Integrationskurse in Bundesländern und Regionen gewählt, die nach dem Königsteiner Schlüssel die meisten Flüchtlinge aufnehmen. Die Wahl fiel auf 42 Kurse bei 16 Trägern in Bayern, Baden-Württemberg, NRW, Hessen und Sachsen. Sachsen wurde aufgenommen, weil im Osten Deutschlands zwar weit weniger Flüchtlinge aufgenommen werden, Sachsen hier jedoch die meisten Flüchtlinge beherbergt. Unter den Trägern befanden sich mehrheitlich Volkshochschulen, aber auch berufsvorbereitende Zentren und kleinere, private Träger.

\section{Durchführung und Auswertung}

Insgesamt verlief die Durchführung der Studie nach Plan. Einschränkend muss angemerkt werden, dass nur 257 Teilnehmer/innen an beiden Umfragen teilnahmen. 349 Befragte beteiligten sich nur an der ersten Umfrage und 264 Befragte nur an der zweiten Umfrage. Diese Zahlen verdeutlichen bereits die enorme Fluktuation, mit der alle Kursträger und Begleitstudien der IKs konfrontiert sind. Über die Hälfte der Teilnehmer/innen wechselte also während unserer Studie in andere Kurse oder erreichte das letzte Kursmodul nicht innerhalb der Zeit unserer Erhebung.

Alle Kursträger zeigten sich sehr zuvorkommend und hilfsbereit. Erklärungen und Erläuterungen der Fragen auf den Tablets erfolgten vor Ort in mehreren Sprachen und es wurde Hilfestellung geleistet, wenn Fragen den Teilnehmenden unklar erschienen. Oft konnten Kursleiter/innen bei der Umsetzung vor Ort zu Rate gezogen und bei der Betreuung der Befragten eingebunden werden. Wenn für manche Angaben oder für die Sprachaufnahmen mehr Privatsphäre benötigt wurde, konnten die Teilnehmer/innen ihren Platz und den Raum mit den Tablets verlassen, da eine räumliche Trennung im Kursraum selbst nicht immer möglich war. Davon machten viele Gebrauch. In der Regel brauchten die Befragten ca. 30 bis 40 Minuten für die Umfrage.

\footnotetext{
Die Sprachen waren Arabisch, Bulgarisch, Deutsch, Englisch, Französisch, Griechisch, Italienisch, Kurdisch (Kurmandschi, nicht Sorani), Persisch, Polnisch, Rumänisch, Russisch, Spanisch, Türkisch, Tigrinya, Ungarisch. Bis auf das Kurdische fanden alle Sprachen Verwendung.
} 
Die elektronischen Datensätze der Teilnehmer/innen wurden in einer Datentabelle zusammengefasst, in mehreren Schritten bereinigt und ins Deutsche übertragen. Angaben zu den Herkunftsländern, geografischen Herkunftsregionen, zum Alter, den Sprachen und Sprachkombinationen der Teilnehmenden wurden auf ihre Sinnhaftigkeit überprüft. In wenigen Fällen waren Angaben offensichtlich inkongruent und wurden aus diesem Grund aus der Datenbasis entfernt. ${ }^{8}$ Nach der ersten Erhebungswelle waren Daten von 606 Teilnehmer/ innen verwertbar.

Um eine Auswertung der Angaben der Geflüchteten vornehmen zu können, bestand ein weiterer Schritt der Datenaufbereitung darin, Kriterien festzulegen, nach denen Teilnehmer/innen als „geflohen“ gelten. Nach dem rechtlichen Aufenthaltstatus wurde in der IDSGoethe-Studie bewusst nicht gefragt, um das gewonnene Vertrauen der Anwesenden nicht zu strapazieren. Stattdessen wurde lose nach dem „Status in Deutschland“ gefragt ohne das Rechtsbegriffe verwendet wurden. Mehrfachangaben waren möglich. Alle, die sich als „Flüchtling“ bezeichneten, wurden später auch als solche geführt. Des Weiteren wurden die Teilnehmer/innen nach den Beweggründen für ihre Migration gefragt. Wer angab, aus Gründen politischer oder religiöser Verfolgung nach Deutschland gekommen zu sein, galt ebenfalls als geflüchtet. Mehrfachnennungen waren möglich, sodass sich Zusammenhänge zu anderen Beweggründen (Bildung, Familie, ökonomische Gründe etc.) betrachten lassen. In der ersten Umfrage waren nach diesen Kriterien 305 der Befragten Geflohene. Nur diese Gruppe fand Eingang in die hier präsentierten statistischen Auswertungen.

Aufgrund unseres Projektschwerpunktes, nämlich der beruflichen Integration von Geflüchteten, widmeten wir den Angaben zu ausgeübten Berufen vor der Ankunft in Deutschland besondere Aufmerksamkeit. Um eine Auswertung dieser Angaben zu ermöglichen, wurden diese freien Angaben nicht nur ins Deutsche übersetzt, sondern mit Kennziffern der Klassifikation der Berufe der Bundesagentur für Arbeit (2011, KldB 2010) assoziiert. Die KldB 2010 gliedert sich nach zwei Aspekten: Zum einen wird durch mehrere Gliederungsebenen die Ähnlichkeit der Berufe („Berufsfachlichkeit“) berücksichtigt. Damit ergeben sich zehn Berufsbereiche, 37 Berufshauptgruppen, 144 Berufsgruppen und 700 Berufsuntergruppen. Der zweite Gliederungsaspekt ist das Anforderungsniveau der jeweiligen Tätigkeit. Die letzte Stelle der fünfstelligen Kennziffer variiert entsprechend zwischen „1 - Helfer- und Anlerntätigkeiten“, , ,2 - fachlich ausgerichtete Tätigkeiten“, ,3-komplexe Spezialistentätigkeiten" und „,4-hoch komplexe Tätigkeiten“. Diese hierarchische Dimension der Gliederung ist für die soziodemografische Auswertung interessant. Ein Beispiel für die Gliederung nach Anforderungsniveau in einem geläufigen Berufsfeld findet sich in Tabelle 2.

\begin{tabular}{|l|l|}
\hline 25101 & Montagehelfer/in \\
\hline 25102 & Maschinenbaumechaniker/in \\
\hline 25103 & Verfahrenstechniker/in \\
\hline 25104 & Ingenieur/in - Verfahrenstechnik \\
\hline
\end{tabular}

Tab. 2: Gliedenung der „Berufe in der Maschinenbau- und Betriebstechnik“ nach Anforderungsniveau

8 So wurden in etwa eindeutige Fehlangaben zum Alter, die auf eine Fehlbedienung des Tablets zurückgehen, annulliert und durch „NA“ (not applicable/available) ersetzt. 
Waren die Angaben der Befragten nicht ausreichend, um eine Zuordnung der angegebenen Berufe zu KlDb-Ziffern vorzunehmen, wurden Angaben anderer Teilnehmer/innen aus dem gleichen Herkunftsland sowie Einschätzungen unserer Mitarbeiter mit Fluchthintergrund zu Hilfe genommen. Ein typisches Beispiel ist die Angabe „Fahrer", die unter Syrern häufig auftrat. Dass darunter höchstwahrscheinlich private Taxifahrer und keine Kraftfahrer gemeint sind, erschließt sich aus dem kulturellen Kontext. Für Fälle, in denen eine Zuweisung nach Anforderungsniveau unmöglich ist, bietet das KldB eine allgemeine Kategorie ,ohne Spezialisierung“, bei denen das Anforderungsniveau entfällt und die Berufsuntergruppe auf „0“ gesetzt wird. Davon machten wir jedoch nur vereinzelt Gebrauch

\section{Ergebnisse}

\subsection{Soziodemografische Eckdaten}

Im Folgenden werden soziodemografische Merkmale der Geflüchteten vorgestellt. Neben dem Alter und dem Geschlecht der Teilnehmer/innen wurde nach den Heimatländern und Herkunftsregionen sowie den Ländern gefragt, in denen sich die Geflüchteten vor der Ankunft in Deutschland aufhielten. Auch die Länge des Aufenthalts sowie die Gelegenheit, im Ausland weitere Sprachen zu erwerben, war Gegenstand der Befragung. Ferner wurde die Anzahl und Art der Arbeitsstellen vor der Ankunft in Deutschland erfasst.

\subsubsection{Alter und Geschlecht}

Die Mehrheit der Teilnehmenden war zwischen 20 und 30 Jahre alt. Das Durchschnittsalter der Geflüchteten in unserem Sample lag bei 30 Jahren. Insgesamt gab es $80 \%$ Männer und 20\% Frauen. Eine Aufteilung nach Kriterien, die sich an typischen Lebensabschnitten orientiert (Studium, Berufseintritt etc.) und einigermaßen paritätische Altersgruppen erzeugt, zeigt, dass der Frauenanteil in jeder Altersgruppe gering war. Am geringsten war er jedoch in den Altersgruppen zwischen 21 und 31 Jahren.

Geschlechterverteilung in den Altersgruppen

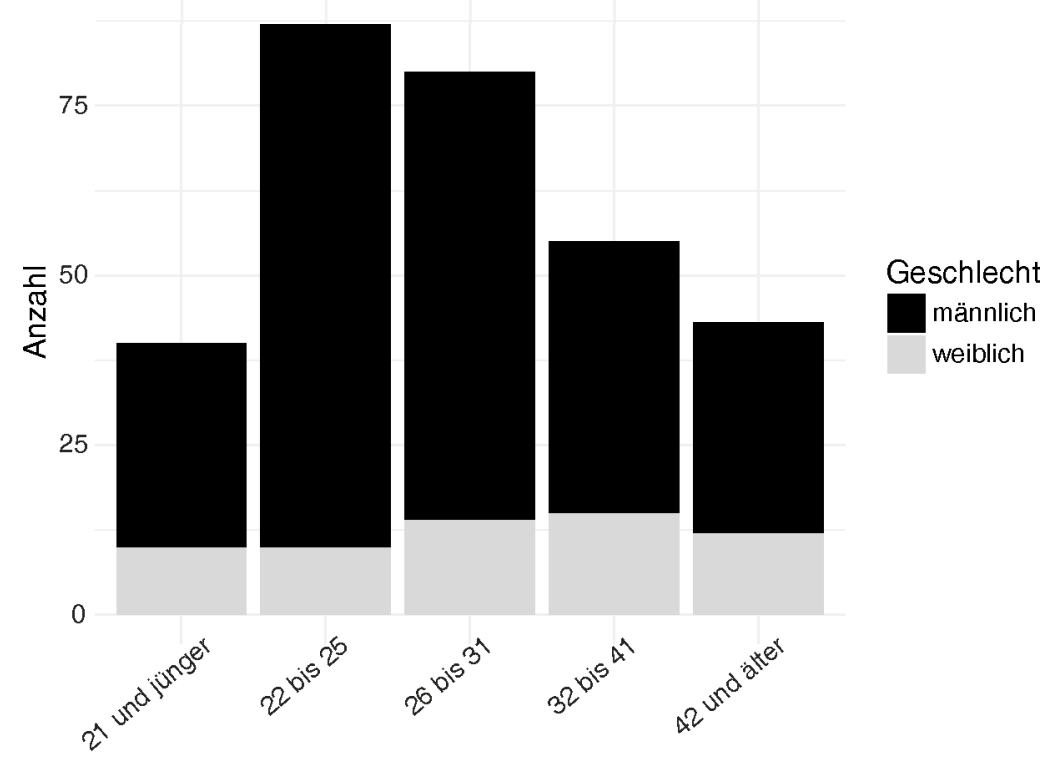

Abb. 1: Verteilung der Befragten auf Alters- und Geschlechtsgruppen 


\subsubsection{Herkunftsländer, Fluchtrouten, Transitländer und Ankunft in Deutschland}

Die Angaben zu Herkunftsländern, zu Fluchtrouten und anderen Aufenthaltsorten sowie zum Aufenthalt in Deutschland sind durch ihre zeitliche Abfolge verbunden. Karte 1 zeigt, dass über $80 \%$ aller Befragten aus verschiedenen Regionen in Syrien und im Irak stammen. ${ }^{9}$ Mehr als elf Teilnehmer/innen kommen jeweils aus Eritrea und dem Iran. Weitaus weniger Teilnehmer/innen stammen aus anderen Ländern des Nahen und Mittleren Ostens und Afrikas.

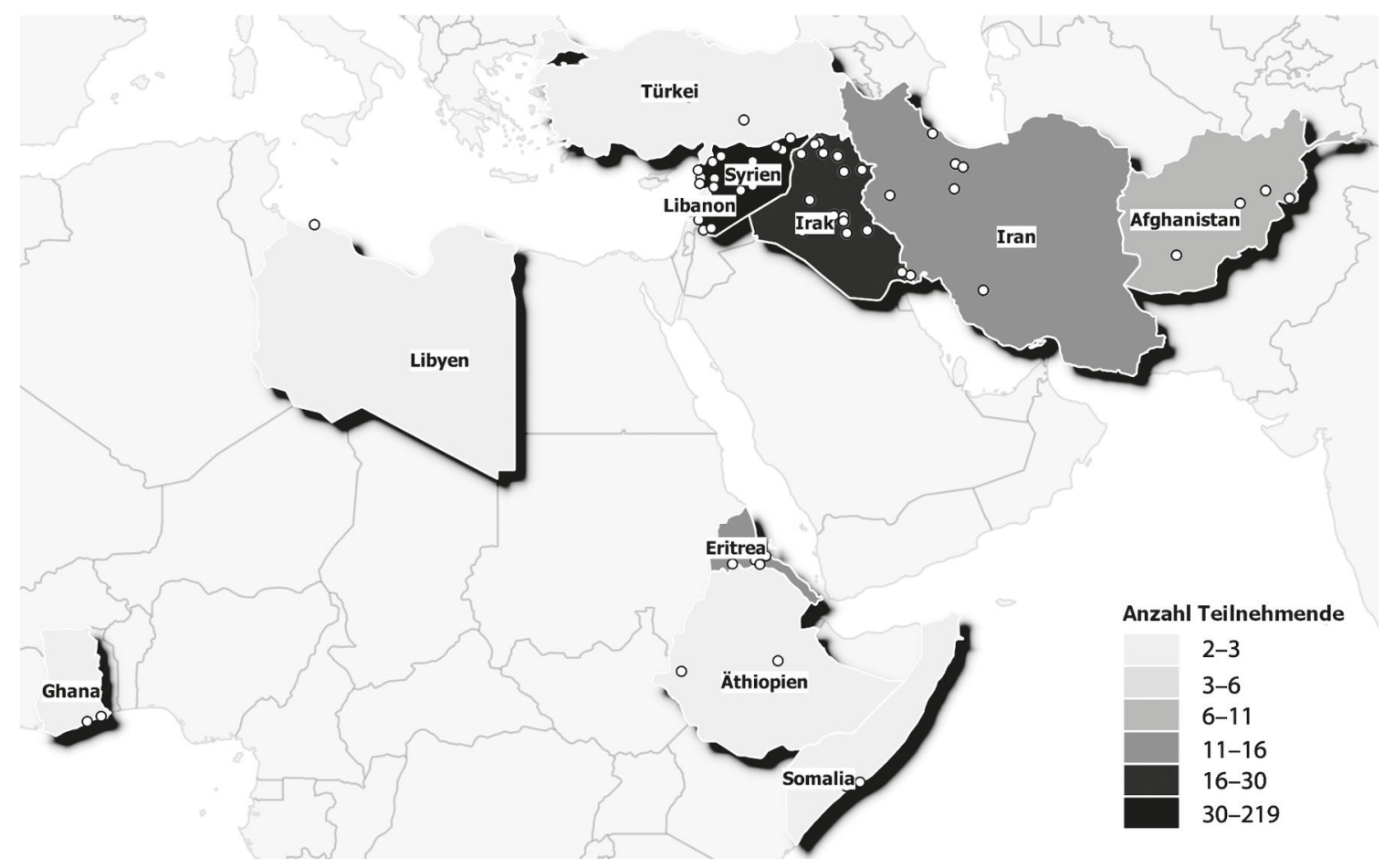

Karte 1: Die wichtigsten Herkunftsländer der Geflüchteten

In der Umfrage wurde zudem nach Ländern gefragt, in denen sich die Teilnehmer/innen vor der Ankunft in Deutschland befanden. Angesichts des Dublin-Übereinkommens (Dublin III), welches bis heute die Asylantragstellung für das erste EU-Land vorsieht, das der Antragssteller oder die Antragstellerin betreten hat, verweigerten viele der Befragten diese Angabe. Trotzdem ergeben sich aus der geografischen Darstellung der Aufenthaltsorte wichtige Fluchtrouten wie etwa die Balkanroute (Karte 2a) oder Wege über andere Transitländer für Flüchtlinge aus dem Nahen und Mittleren Osten (Karte $2 \mathrm{~b}$ und $2 \mathrm{c}$ ). Die Türkei wurde beispielsweise von 26 Geflüchteten als Aufenthaltsland genannt. Für Personen aus Ostafrika waren die arabischsprachigen Länder Libyen und Sudan Transitländer mit längeren Aufenthalten (Karte 2d). Solche Aufenthalte schlagen sich auch in den Sprachbiografien der Geflüchteten nieder, wie wir in Abschnitt 6.2.3 genauer beschreiben.

9 Karte 1 bildet die Geburtsländer der Befragten ab. Zwölf Teilnehmende gaben an, in einem anderen Land als ihrem Geburtsland aufgewachsen zu sein. Allerdings machten nur zwei Teilnehmende eine konkrete Angabe zu diesen Ländern. 


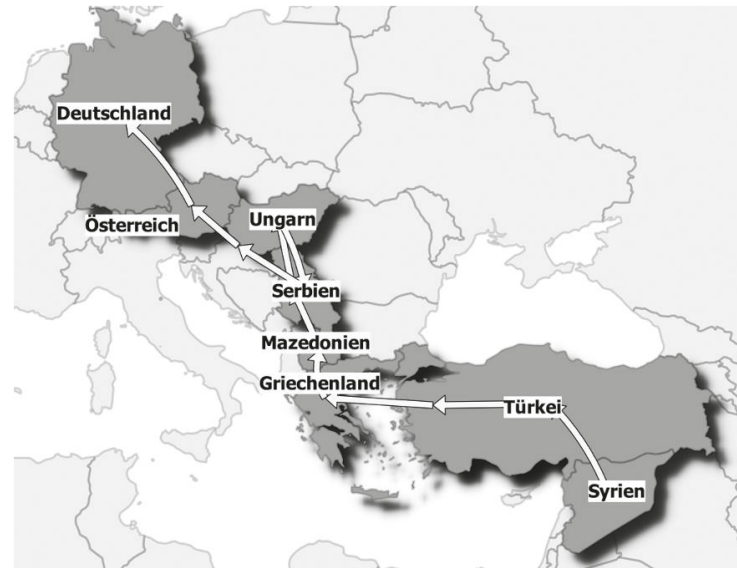

a

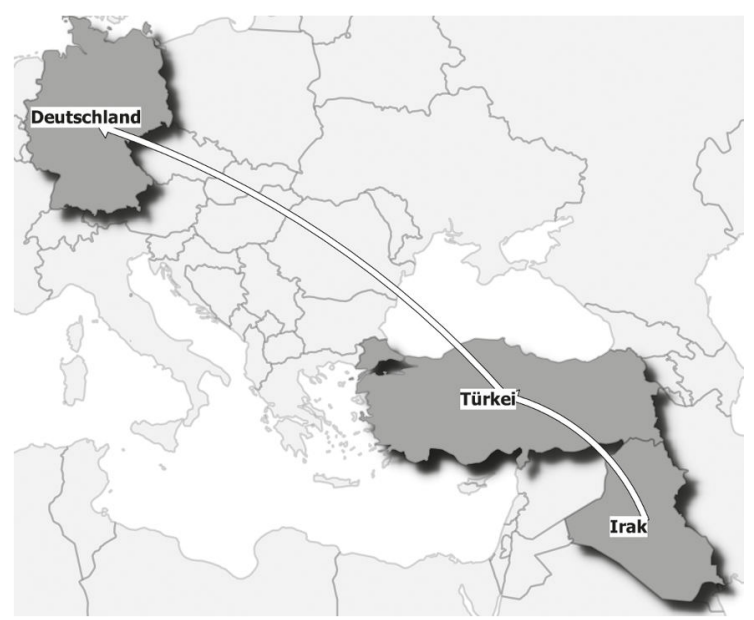

b

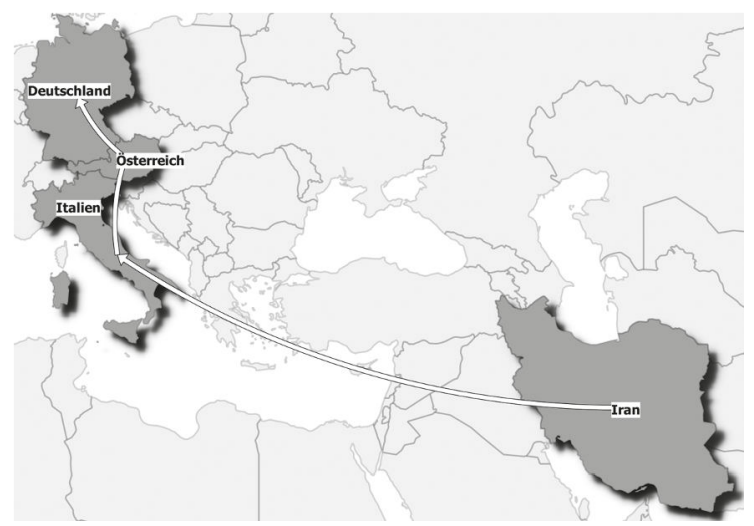

C

Karten 2a, b, c: Wichtige Transitländer auf der Flucht aus dem Nahen und Mittleren Osten

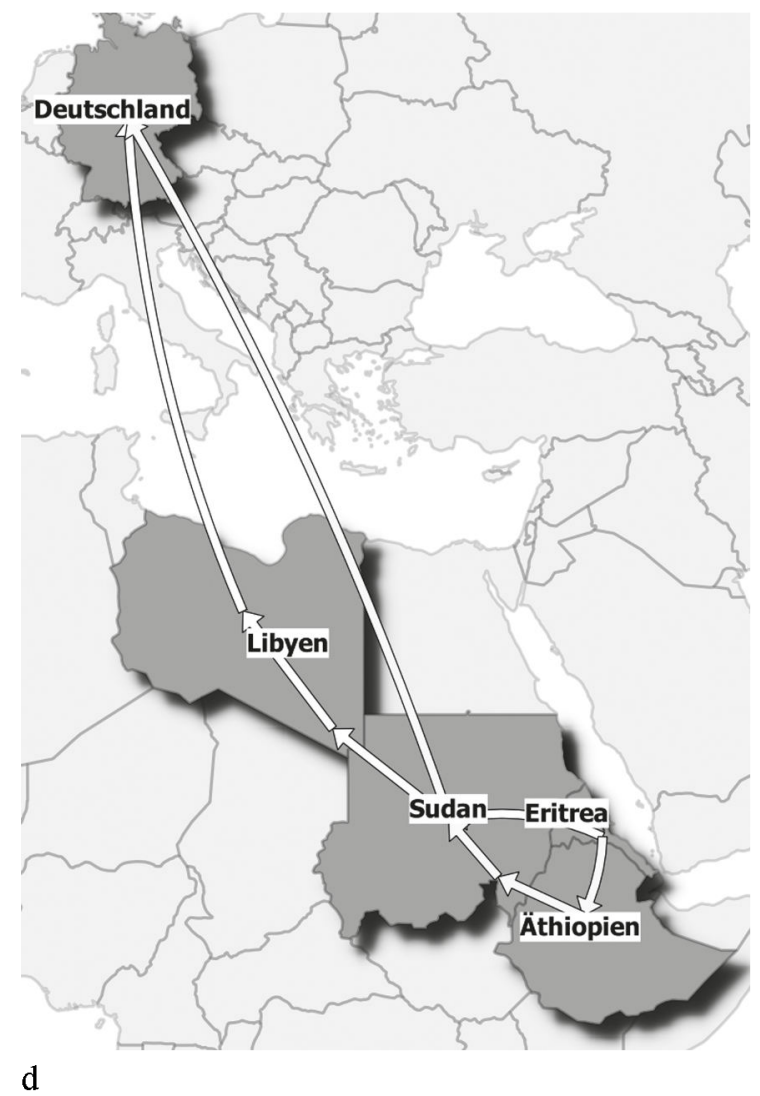

Karte 2d: Wichtige Transitländer auf der Flucht aus Ostafrika

Im Hinblick auf die Massenflucht von 2015 findet das Dublin-Abkommen auch deswegen kaum Anwendung, weil fast alle Antragsteller/innen auf ein Asylverfahren bereits länger als drei Monate in Deutschland leben und eine Rückführung ins Erstaufnahmeland nach dieser Zeit nicht mehr möglich ist. 70\% aller Angaben in unserer Umfrage beschreiben im Jahr 2016 einen Aufenthaltszeitraum von sieben bis 18 Monaten. 


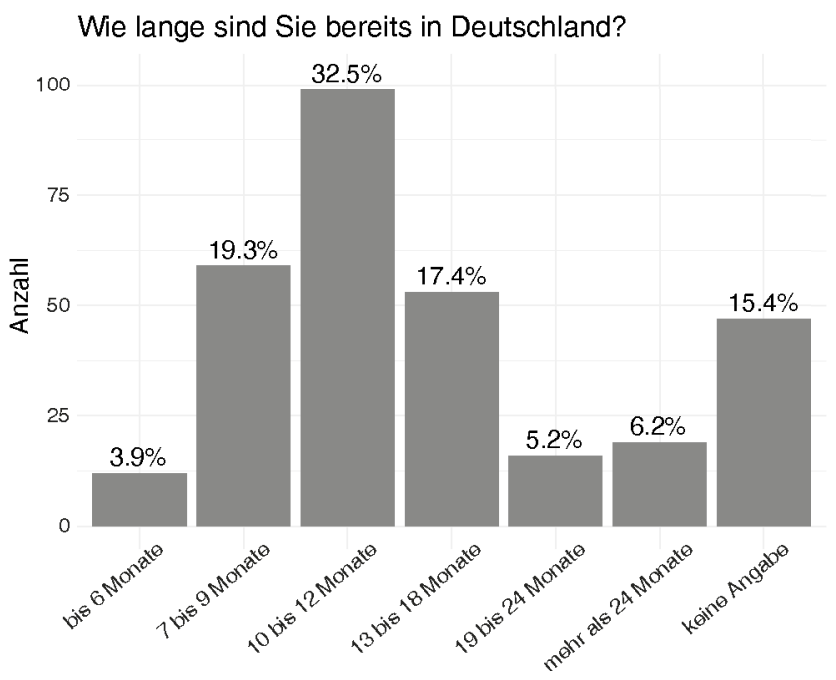

Abb. 2: Aufenthaltsdauer in Deutschland

\subsubsection{Bildungshintergründe}

Die Anzahl der Teilnehmenden ohne jegliche Schulbildung war zur Zeit unserer Erhebung in den Integrationskursen sehr gering, da parallel zu den allgemeinen Kursen eigens Kurse für Analphabeten und Schriftlernende angeboten wurden. Im Durchschnitt besuchten die Befragten unserer Erhebung ca. $12(11,8)$ Jahre verschiedene Bildungseinrichtungen. Ein großer Anteil verbrachte 12 bis 18 Jahre mit der Ausbildung - auch an Hochschulen und Universitäten. Dies verweist auf eine Differenzierung nach Bildungshintergründen, die mit anderen Faktoren wie zum Beispiel der Arbeitserfahrung in wechselseitiger Beziehung stehen können.

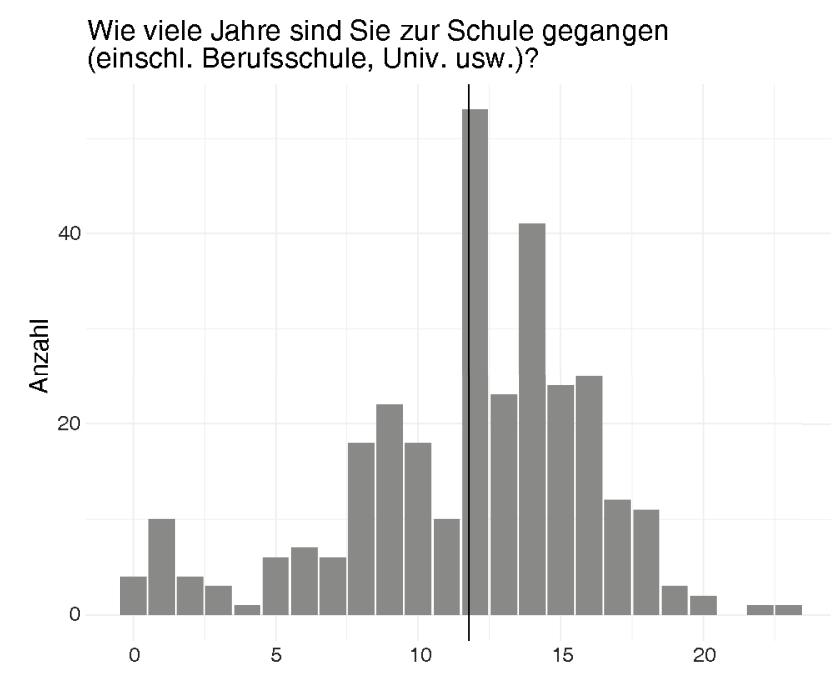

Abb. 3: Anzahl der formalen Bildungsjahre der Befragten. Die senkrechte Linie gibt den Mittelwert an (11,8 Jahre).

\subsubsection{Arbeitsverhältnisse vor der Ankunft in Deutschland}

Die Befragten wurden gebeten, alle Arbeitsstellen anzugeben, die sie vor ihrer Ankunft in Deutschland innehatten. Bis zu fünf Angaben waren möglich. Ziel war es, alle Berufe zu erfassen, die die jeweilige Person im bisherigen Leben erlernt bzw. ausgeführt hatte, 
um so auch berufliche Karrieren nachzeichnen zu können. Die Beschreibung der Berufe wurde so gut wie möglich ins Deutsche übertragen und anschließend anhand der KldB 2010 unterteilt (siehe Abschn. 4). Insgesamt wurden im Datensatz 168 unterschiedliche Berufe genannt. Etwas weniger als ein Drittel (89 Personen, 29,2\%) gab an, dass sie vor ihrer Ankunft in Deutschland nicht gearbeitet hätten (siehe Abb. 4). Zu dieser Gruppe zählen wir auch sieben Befragte, die zwar angaben, vor ihrer Ankunft in Deutschland gearbeitet zu haben, aber keine Angaben zu ihren ausgeübten Tätigkeiten machten. Von den gut $70 \%$ (216 Personen) mit Arbeitserfahrung hat rund die Hälfte (114 Personen) ausschließlich Berufserfahrungen in einfachen Berufen gemacht. Die andere Hälfte (102 Personen) hat in mindestens einem komplexen Beruf gearbeitet. Ca. $43 \%$ der im Herkunftsland berufstätigen Teilnehmer/innen hatten nur einen Beruf, ca. $44 \%$ hatten zwei bis drei Berufe.

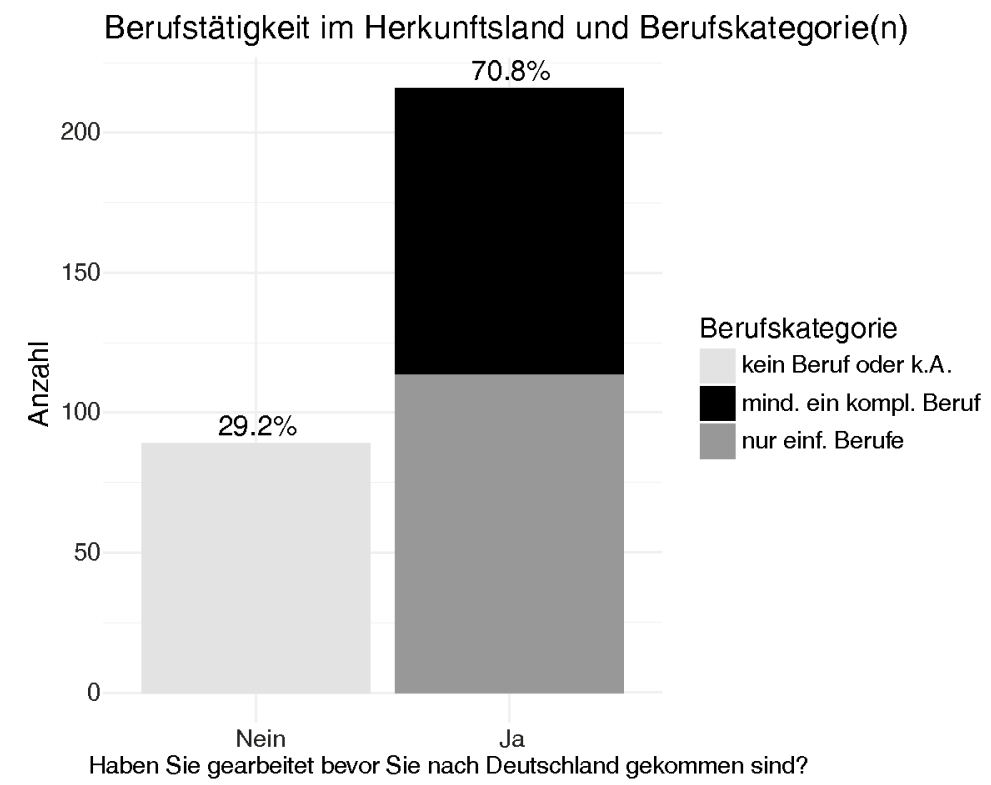

Abb. 4: Arbeitserfahrung im Herkunftsland und Berufskategorie

Wie viele Jobs hatten Sie, bevor Sie nach

Deutschland gekommen sind?

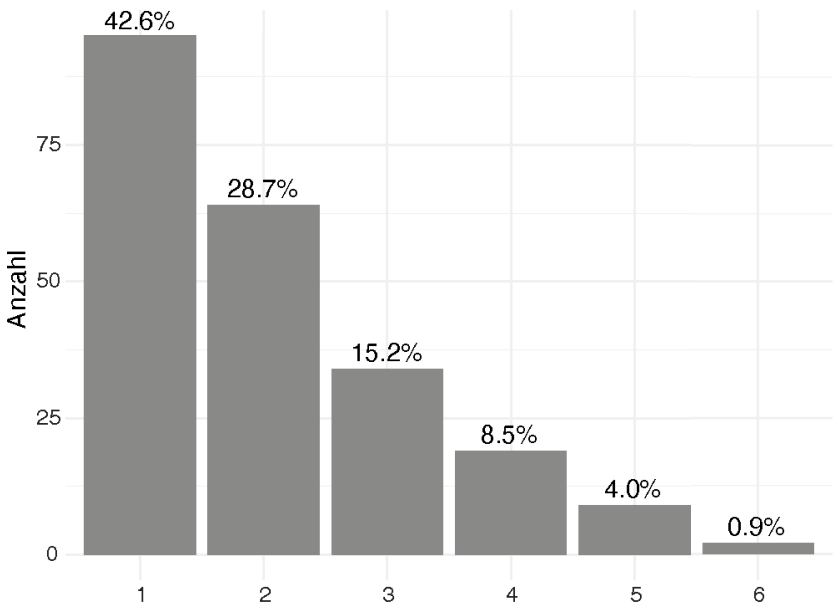

Abb. 5: Anzahl der Berufe derjenigen, die im Herkunftsland gearbeitet haben 
Interessant ist an dieser Stelle ein Vergleich mit einigen Ergebnissen der IAB-BAMFSOEP-Studie zur Erwerbstätigkeit von Flüchtlingen in ihrer Heimat. Laut dieser Studie waren 30\% der Befragten als Arbeiter, 25\% als Angestellte ohne Führungsposition, 13\% als Angestellte mit Führungsposition und 27\% als Selbstständige tätig. Addiert man die Arbeiter und Angestellten auf der einen Seite sowie die Führungskräfte und Selbstständigen auf der anderen Seite zu einfachen und komplexen Berufen zusammen, ergibt sich ein prozentuales Verhältnis von $55 \%$ zu $40 \%$. Das Verhältnis in der IDS-Goethe-Studie ist zwar ausgeglichener, weist jedoch ebenfalls auf eine relativ hohe Zahl komplexer Berufserfahrungen hin.

Unter den befragten Flüchtlingen in der IDS-Goethe-Studie kann die Branchenzugehörigkeit der Berufe, die von ein und derselben Person ausgeübt wurden, stark variieren. Durch die Klassifikation nach Komplexitätsgraden zeichneten sich auch Berufsmuster ab, die auf Lebensläufe mit zunehmend komplexeren Tätigkeiten schließen lassen. In Abbildung 6 ist eine Aufschlüsselung aller angegebenen Berufe nach Berufsfeldern (vertikal) und hierarchischen Kategorien (horizontal) der KldB 2010 (Bundesagentur für Arbeit 2011) dargestellt. Es zeigt sich, dass Arbeitserfahrungen in Anlern- und Helfertätigkeiten eher selten vorkommen. In der Komplexitätskategorie „fachlich ausgerichtete Tätigkeiten“ liegen die Schwerpunkte der Berufsangaben insbesondere in den Bereichen „kaufmännische Dienstleistungen, Handel, Tourismus“ und „Rohstoffgewinnung, Produktion, Fertigung“. Weitere Schwerpunkte befinden sich im Bereich „Gesundheit, Soziales und Erziehung“, „Verkehr, Logistik, Sicherheit" und „Bau, Vermessung, Gebäudetechnik“. Die komplexen und hochkomplexen Tätigkeiten verteilten sich vor allem auf die Bereiche "Gesundheit, Soziales und Erziehung“ sowie „Verwaltung, Buchhaltung“.

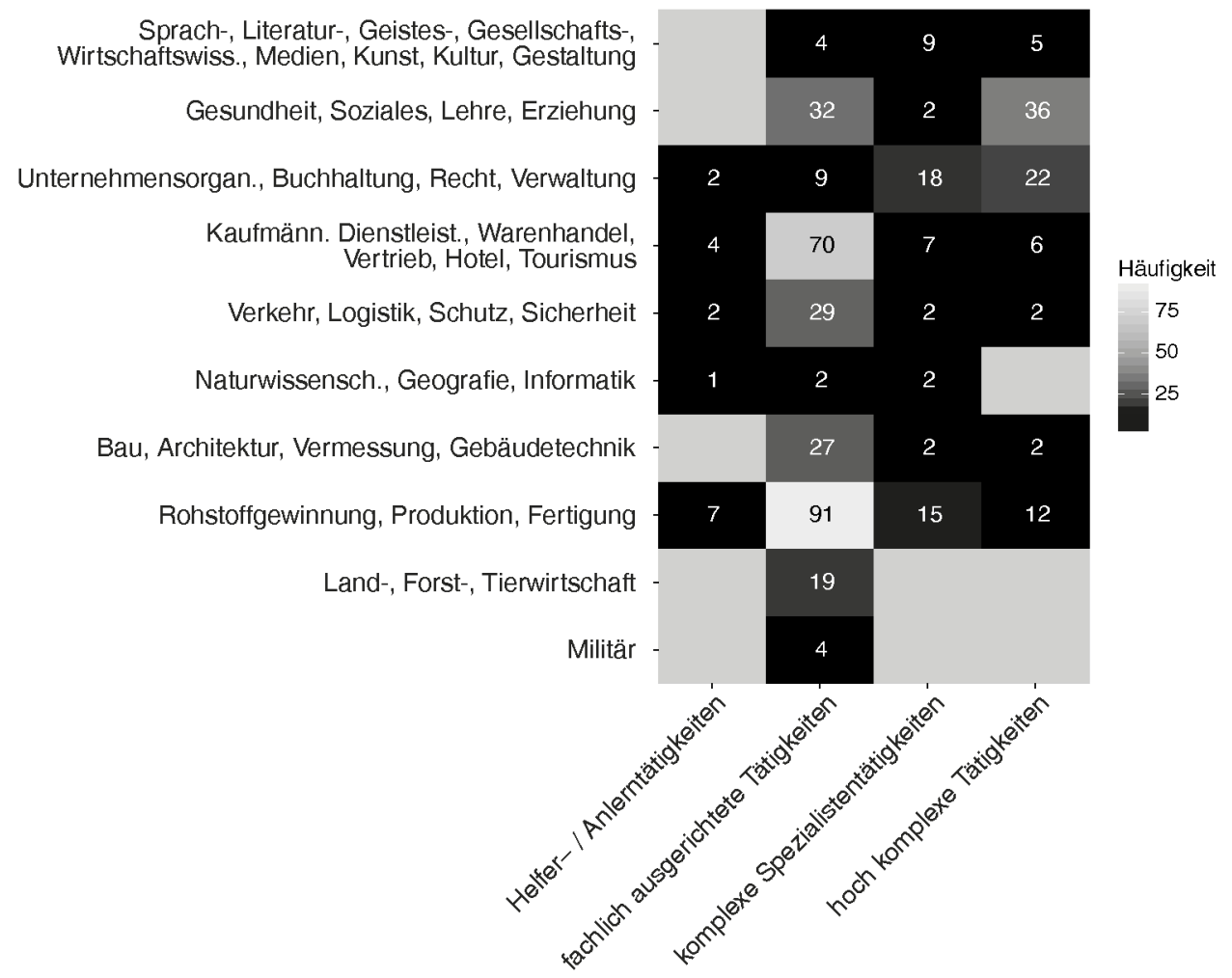

Abb. 6: Kreuztabelle der Berufsfelder (vertikal) und der vier Komplexitätsstufen der Berufe (horizonal). Der Grauton korrespondiert mit der Anzahl der Angaben in der jeweiligen Zelle (dunkelgrau: weniger; hellgrau: mehr). Graue Zellen sind unbesetzt. 


\subsection{Sprachliche Hintergründe und Sprachbiografien}

Die demografischen und biografischen Angaben wurden in der IDS-Goethe-Studie immer im Zusammenhang mit Angaben zum Spracherwerb und Sprachgebrauch in der jeweiligen, beschriebenen Lebenssituation gemacht. So erhielten wir Informationen zu den ungesteuert erworbenen ersten Sprachen, religiösen Sprachen, Bildungssprachen, Berufssprachen und weiteren Sprachen, die auf dem Weg nach Deutschland erworben wurden. Aus diesen Angaben konnten individuelle Sprachbiografien nachgezeichnet werden. Im Folgenden untersuchen wir zunächst die Erstsprachen, die bis zum Alter von fünf Jahren erworben wurden, um sowohl die Sprachvielfalt, aber auch die Rolle der nativen Mehrsprachigkeit zu verdeutlichen. Eine Darstellung aller Sprachbiografien ist aufgrund der zahlreichen unterschiedlichen Herkunftssprachen und Herkunftsländer nicht möglich. Nach einer Zählung der Fremdsprachen, die in Schule und Beruf zusätzlich erworben wurden, nehmen wir daher für die syrischen und eritreischen Flüchtlinge gesonderte Visualisierungen der gruppenspezifischen Sprachbiografien vor. So werden Gemeinsamkeiten und Unterschiede verschiedener Herkunftsgruppen deutlich.

\subsubsection{Erstsprachen bis zum Alter von fünf Jahren}

Als Erstsprachen bezeichnen wir im Folgenden alle Sprachen, die bis zum fünften Lebensjahr auf ungesteuerte Weise erworben wurden. Dies schließt den klassischen Begriff der "Muttersprachen“, die im familiären Umfeld erworben werden, aber auch oft gesprochene Sprachen des sozialen Umfeldes oder frühe Kontaktsprachen mit ein. Mehrfachangaben waren bei jeder Frage möglich. Wichtig war uns außerdem, die Selbstbeschreibung der Sprachen durch die Sprecher/innen bei der Übersetzung möglichst nicht zu verändern, da Sprachbezeichnungen starker Subjektivität unterliegen und eine klare Abgrenzung zu Dialekten ohnehin nicht möglich ist. Dies kann jedoch zu starken Verallgemeinerungen führen. Lokal gesprochene Varietäten des Arabischen unterscheiden sich beispielsweise erheblich voneinander und auch vom später in der Schule erlernten Hocharabisch (Fuṣhā).$^{10}$ Diese Situation ist bei den folgenden Angaben zu beachten.

Rund 7\% der Befragten machen keine Angabe zu ihrer ersten Sprache. Bei rund 55\% aller befragten Flüchtlinge handelt es sich um monolinguale Arabischsprecher/innen. Weitere 18\% der Befragten wuchsen in einer mehrsprachigen Konstellation mit dem Arabischen auf. Diese Angaben passen zum starken Gewicht der Region Syrien/Irak unter den Befragten. Die Sprachen, die von diesen 55 Teilnehmer/innen zusammen mit dem Arabischen genannt wurden, waren die Minderheitensprachen Kurdisch, Turkmanisch, Assyrisch (Akkadisch) und Armenisch, aber auch das Englische, Türkische und Persische.

Neben weiteren Sprachen aus dem Nahen und Mittleren Osten (Persisch, Kurdisch, Dari, Paschtunisch, Urdu) sind auch einige Sprachen Ost- und Westafrikas vertreten. Aus Afrika kommen auch die meisten Sprecher/innen, die als Kind mit vier oder gar fünf Sprachen aufgewachsen sind. In einem Extremfall sind dies zum Beispiel Damgbe, Englisch, Ewe, Ga und Twi. So ausgeprägt ist Mehrsprachigkeit in jungen Jahren jedoch laut Selbstangabe nur bei etwa 4\% der Befragten. Ca. 16\% der Teilnehmenden hatten zwei Erstsprachen und ca. $5 \%$ wuchsen dreisprachig auf.

10 So wird etwa der in Syrien beheimatete levantische Dialekt von nordafrikanischen Arabischsprechenden teilweise verstanden, weil er eine größere Nähe zum schulsprachlichen Hocharabischen aufweist. Die in Nordafrika beheimateten Dialekte sind hingegen für syrische Arabischsprechende oft unverständlich. 


\section{Erstsprachen der Geflüchteten}

Arabisch
Arabisch, Kurdisch
k.A.
Arabisch, Englisch
Tigrinya
Persisch
Kurdisch
Dari
Somalisch

Arabisch, Kurdisch, Türkisch

Ungarisch

Türkisch

Russisch, Ukrainisch

Rumänisch, Russisch

Portugiesisch, Spanisch

Persisch, Türkisch

Paschtunisch

Panjabi, Urdu

Kotokoli

Jesidisch

Deutsch, Englisch, Französisch, Italienisch

Dari, Persisch

Dari, Paschtunisch

Damgbe, Englisch, Ewe, Ga, Twi

Aserbaidschan-Türkisch, Gilaki, Persisch

Arabisch, Turkmanisch Arabisch, Türkisch

Arabisch, Persisch

Arabisch, Französisch

Arabisch, Englisch, Türkisch

Arabisch, Englisch, Persisch

Arabisch, Englisch, Kurdisch, Türkisch

Arabisch, Englisch, Französisch

Arabisch, Deutsch, Englisch, Türkisch

Arabisch, Assyrisch (Akkadisch), Türkisch

Arabisch, Armenisch, Kurdisch, Syrisch

Amharisch, Englisch, Tigrinya

Amharisch, Englisch, Oromo

Amharisch, Englisch, Italienisch, Tigrinya

Albanisch

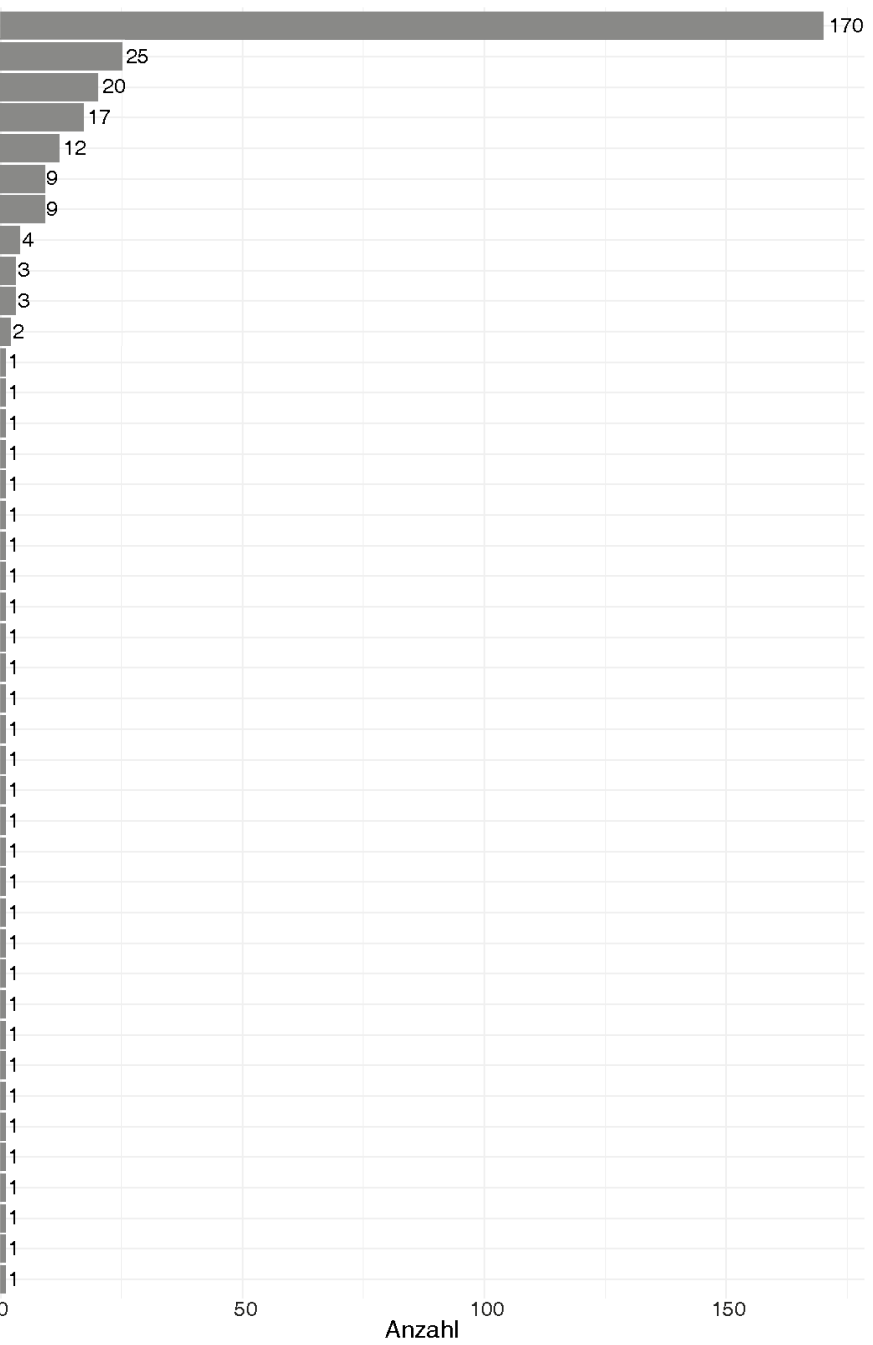

Abb. 7: Erstsprachen bzw. Erstsprachkombinationen der Befragten

\section{Erstsprachen}

Wie viele Sprachen als Kind (1-5 J.) in und außerhalb der Familie gesprochen/gelernt?

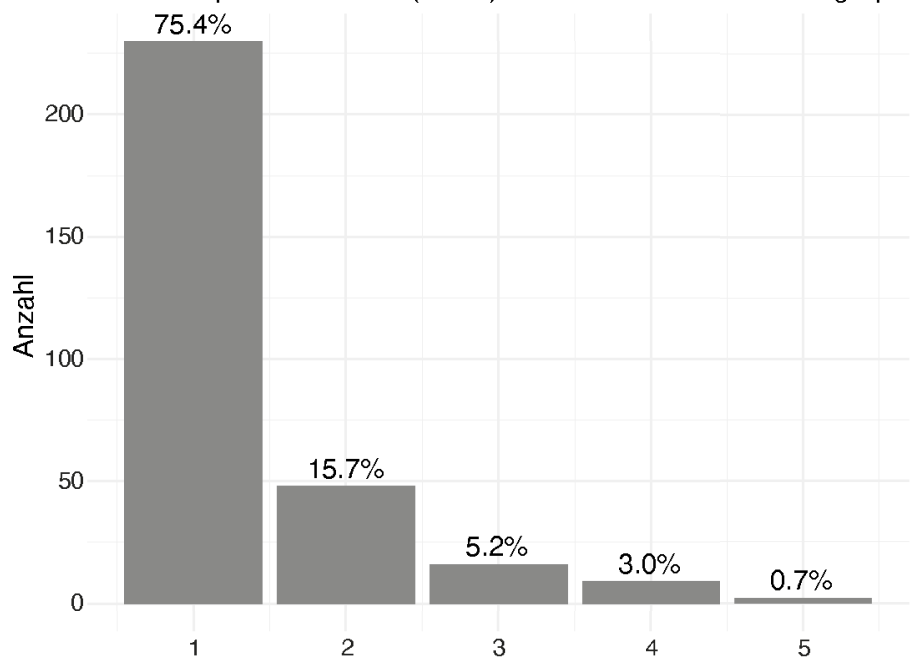

Abb. 8: Anzahl der Erstsprachen 


\subsubsection{Fremdsprachen in Schule und Arbeitsleben}

Mit dem Eintritt in die Schule ändert sich der Blick unserer Erhebung auf die Sprachangaben. Neu erworbene Sprachen bezeichnen wir nun bewusst als Fremdsprachen, weil sich die Erwerbsumstände wesentlich von den Umständen im familiären und nachbarschaftlichen Umfeld der frühen Kindheit unterscheiden. Dabei stellen neu erworbene Unterrichtssprachen, wie etwa der Erwerb des Arabischen in Syrien durch kurdische Muttersprachler/ innen, natürlich einen gesonderten Fall dar, weil sie im Gegensatz zum Englischen oder Französischen im Unterricht vorausgesetzt werden. Diese Unterschiede werden im nächsten Abschnitt visualisiert und sind im Folgenden nicht berücksichtigt. Für eine bessere Aussagekraft schließt Abbildung 9 nur die Sprachen ein, die in der Grundschule und in der weiterführenden Schule erworben wurden. Sprachen, die während des Studiums erworben wurden, wurden aufgrund der geringen Zahl ausgeblendet.

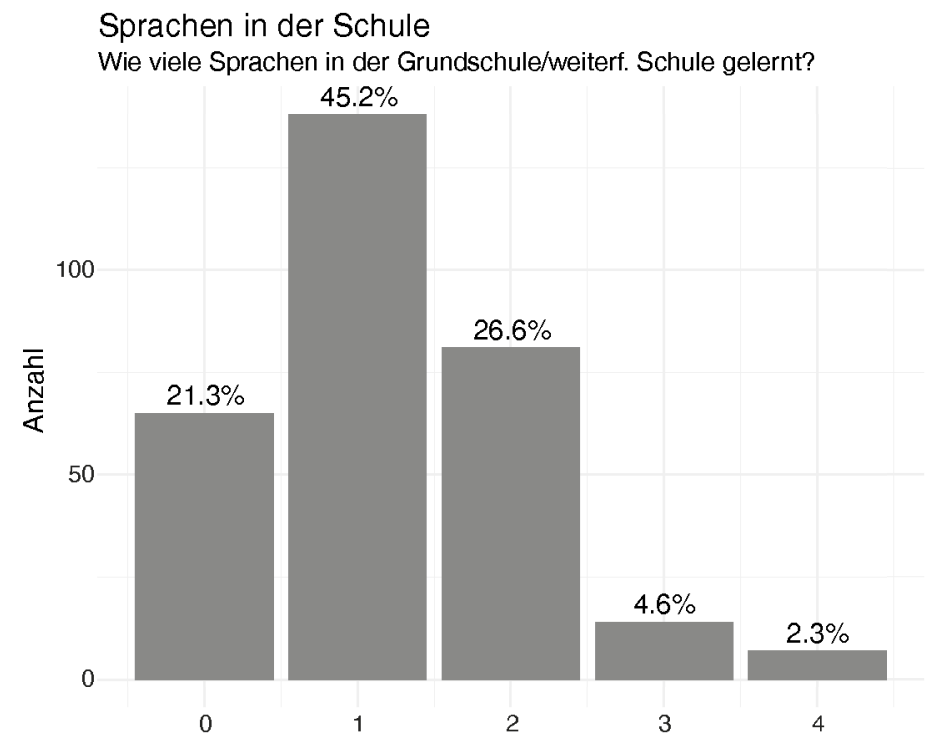

Abb. 9: Anzahl der in der Grundschule und weiterführenden Schule gelernten Fremdsprachen

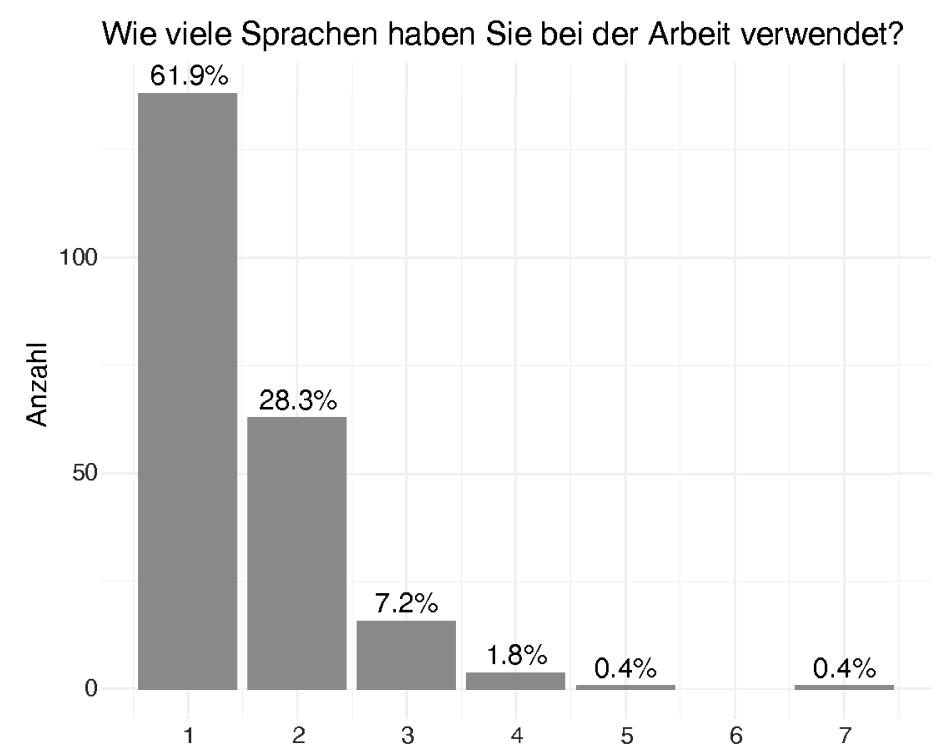

Abb. 10: Anzahl der während der Arbeit verwendeten Sprachen 
Abbildung 9 verdeutlicht, dass rund ein Fünftel der Geflüchteten angibt, keine neue Sprache in der Grundschule gelernt zu haben. Etwa 45\% der Befragten erwarben genau eine Fremdsprache in der Schule. Ein Viertel erwarb zwei Fremdsprachen. Ca. 7\% erwarben drei oder vier Fremdsprachen in der Schule. Abbildung 10 schließt alle angegebenen Sprachen im Arbeitsleben mit ein. Rund ein Viertel der Befragten machte keine Angabe zum beruflichen Sprachgebrauch. Etwa 62\% der Teilnehmer/innen nutzten im Arbeitsumfeld immer dieselbe Sprache. Ca. 28\% der Befragten verwendeten immerhin zwei Sprachen im Arbeitsleben. Alle weiteren Angaben fallen kaum ins Gewicht.

\subsubsection{Kollektive sprachbiografische Darstellungen}

Eine Quantifizierung sprachbiografischer Angaben wurde in der Migrationslinguistik unseres Wissens nach bisher nicht unternommen (siehe Abschn. 2). Durch die Zusammenfassung individueller Erfahrungen entsteht ein neuer Blick auf die Zusammenhänge. Allerdings muss dieser Schritt gezielt vorgenommen werden. Aus den soziodemografischen Daten und den Angaben zum Spracherwerb entstünde bei der Betrachtung aller Befragten auf Grund der unterschiedlichen Erstsprachen und Herkunftsländer ein extrem komplexes Bild mit schwer vergleichbaren Erwerbssituationen. Es ist daher sinnvoll, sich bei der Betrachtung von sprachbiografischen Verläufen auf Personengruppen gemeinsamer Herkunft zu konzentrieren, weil sich die Erwerbssituationen in diesen Fällen zumindest strukturell ähneln (gleiche Schulform, ähnliche Fluchtroute etc.). Im Folgenden geben wir einen Überblick über die Befragten aus Syrien und die deutlich kleineren Personengruppen aus Eritrea und dem Iran. In der Umfrage machten die Teilnehmer/innen ihre Sprachangaben immer im Zusammenhang mit Angaben zu vergangenen Lebensabschnitten. Es wurden die folgenden Lebensabschnitte unterschieden: die frühe Kindheit (Geburt bis fünf Jahre, Zeitraum zum Erwerb einer „Erstsprache“), die Grundschulzeit, die Zeit der weiterführenden Schule oder Sekundarschule (oft in die Pubertät fallend), die Zeit der akademischen Ausbildung (Studium an einer Hochschule oder Universität), das Berufsleben (das gesamte bisherige Arbeitsleben) und die Flucht als Zeitpunkt, der der Erhebung am nächsten ist. Es ist wichtig, diese Abschnitte nicht streng chronologisch zu verstehen. Für manche der Befragten fehlen zum Beispiel Angaben zum Arbeitsleben, während Angaben zum Sprachgebrauch auf der Flucht vorhanden sind. Ebenso ist es möglich, dass parallel zum Studium gearbeitet wurde. Die Abschnitte „Arbeit“ und „Flucht“ können zudem für die Befragten unterschiedlich lang sein. In den Darstellungen beschränken wir uns auf die fünf häufigsten Sprachen für jede Gruppe.

\subsubsection{Kollektive Sprachbiografien: Geflüchtete aus Syrien}

Im Fall der Befragten aus Syrien sind die fünf häufigsten Sprachen das Arabische, das Englische, das Französische, das Türkische und das Kurdische. Ca. 90\% der aus Syrien Stammenden geben das Arabische als „Erstsprache“ an. Nur wenige erwerben das Arabische erst mit Eintritt in die Schule. Die Angaben bleiben danach konstant, das heißt das Arabische wird in späteren Lebensabschnitten nicht mehr erlernt. Eine weitere Sprache, die ihren Wert weitgehend konstant hält, ist das Kurdische. $\mathrm{Ca} .10 \%$ der Befragten aus Syrien geben es als Erstsprache an, danach ändert sich der Status des Kurdischen nicht mehr. Als typische "Schulsprachen" fallen das Englische und das Französische ins Gewicht. Englisch erwerben ca. 50\% der Befragten bereits in der Grundschule, Französisch ca. 10\%. Beide Sprachen gewinnen unterschiedlich an Bedeutung: das Englische fällt für über $70 \%$ in den weiterführenden Schulen und Universitäten ins Gewicht und erreicht seinen Höhepunkt für die Syrer/innen mit 80\% im Berufsleben und auf der Flucht. 
Das Französische spielt für ca. ein Viertel der Syrer/innen eine gewisse Rolle bei Ausbildung, Beruf und Flucht. Interessant ist die Entwicklung des Türkischen: es spielt als schulische Fremdsprache praktisch keine Rolle, nimmt im Beruf aber für knapp 10\% der Befragten eine gewisse Rolle ein. Über $20 \%$ der Befragten geben an, bei der Flucht mit dem Türkischen in Kontakt gekommen zu sein. Damit wurde das Türkische vor allem außerhalb formeller Bildungskontexte erworben und gebraucht.

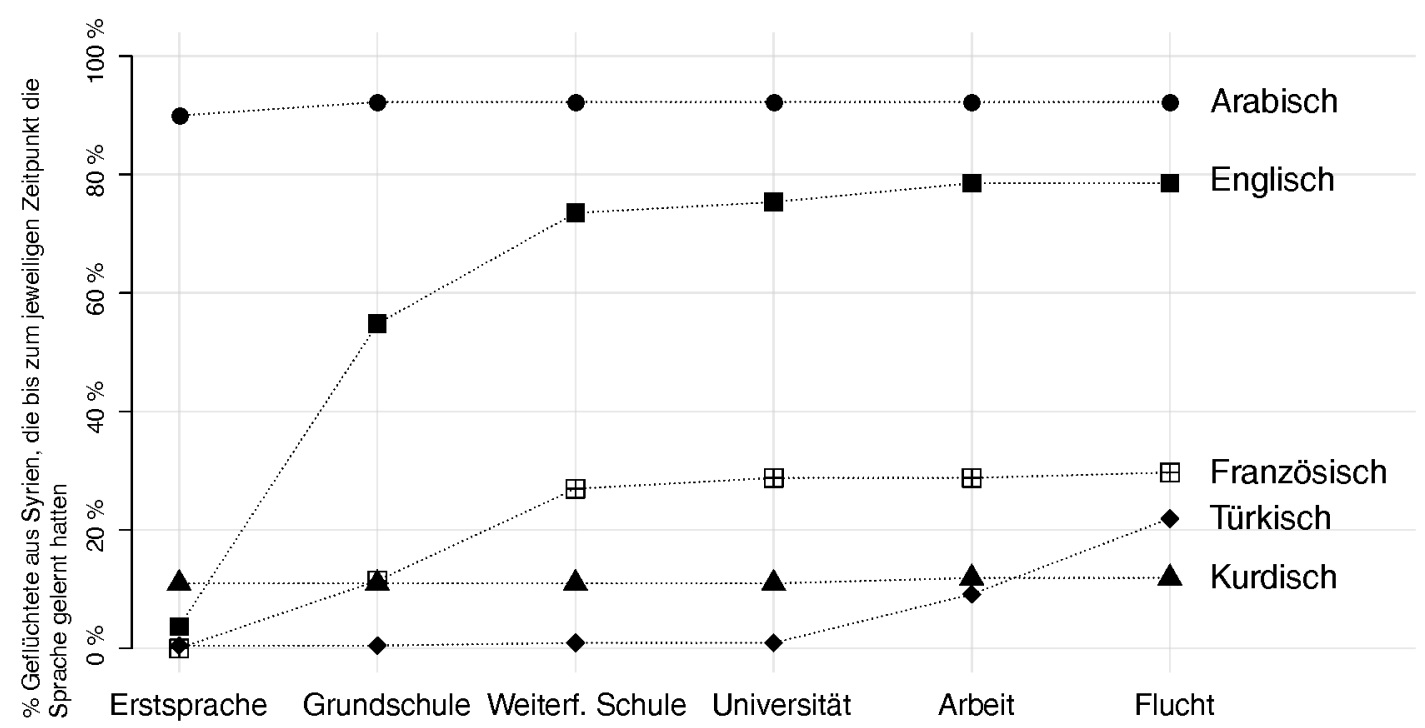

Abb. 11: Verlauf des Erwerbs der fünf häufigsten Sprachen bei den syrischen Flüchtlingen ${ }^{11}$

Es ist wichtig zu erwähnen, dass alleine die Angabe über die Erwerbszeitpunkte von Sprachen im Leben keine Aussagen über die Relevanz verschiedener Sprachen in unterschiedlichen Lebensabschnitten zulässt. Um diesen Punkt zu untersuchen, wurde in der Umfrage die Gebrauchsfrequenz der angegebenen Erst- und Fremdsprachen zu drei Zeitpunkten im Leben erfragt. $\mathrm{Zu}$ allen angegebenen Sprachen bewerteten die Befragten die Häufigkeit des Gebrauchs im Alter von fünf Jahren, 15 Jahren und zum Zeitpunkt der Befragung. Abbildung 12 enthält die Häufigkeitsverteilungen des Arabischen, des Englischen, des Französischen und des Türkischen. Für das Arabische wird klar, dass es nach der Flucht etwas an Bedeutung einbüßt, auch wenn zu Beginn des IKs immer noch die Mehrheit angibt, meistens oder fast immer auf Arabisch zu kommunizieren. Das Gegenteil ist für das Englische der Fall: Schon im Übergang von fünf zu 15 Jahren ist ein deutlicher Anstieg der Kategorie „manchmal“ zu sehen. Nach Eintreffen in Deutschland wachsen dann auch die Kategorien „meistens" und „die Hälfte der Zeit“.

Des Weiteren zeigt sich, wie das Französische und das Türkische zu unterschiedlichen Zeiten im Leben unterschiedlich oft Verwendung finden. Beim Französischen lässt sich ein klarer Kontrast der Schulzeit (15 Jahre) zu den beiden anderen Zeitpunkten feststellen. Nur hier wird von einem guten Drittel der Sprachlerner ,manchmal“ bis „,meistens“ Französisch gesprochen. Insgesamt wird aber deutlich, dass das Französische in keiner Lebensphase dominiert. Auch das Türkische ist nie dominant.

Insbesondere für das Türkische fällt auf, dass zu den Lebenszeitpunkten „Kindheit“ und „Jugend" sehr oft keine Angaben vorliegen, weshalb die Gesamthöhe des dritten Balkens deutlich ansteigt. Trotzdem kommt bei wenigen Personen mit fünf und 15 Jahren die

11 Eine farbige Version dieser Grafik findet sich unter dib.ids-mannheim.de unter der Kategorie „Erhebung“. 
Kategorie „fast immer“ vor. Am stärksten verliert das Türkische insgesamt während der Schulzeit an Bedeutung - und verhält sich damit praktisch gegenteilig zum Französischen. Zum heutigen Zeitpunkt gewinnt das Türkische wieder an Bedeutung, wobei der ständige Gebrauch nicht mehr belegt wird. Insbesondere der Anstieg der Kategorie "manchmal" macht deutlich, dass das Türkische auch in Deutschland für etliche Sprecher einen interessanten Stellenwert als gelegentliche Gebrauchssprache einnimmt.
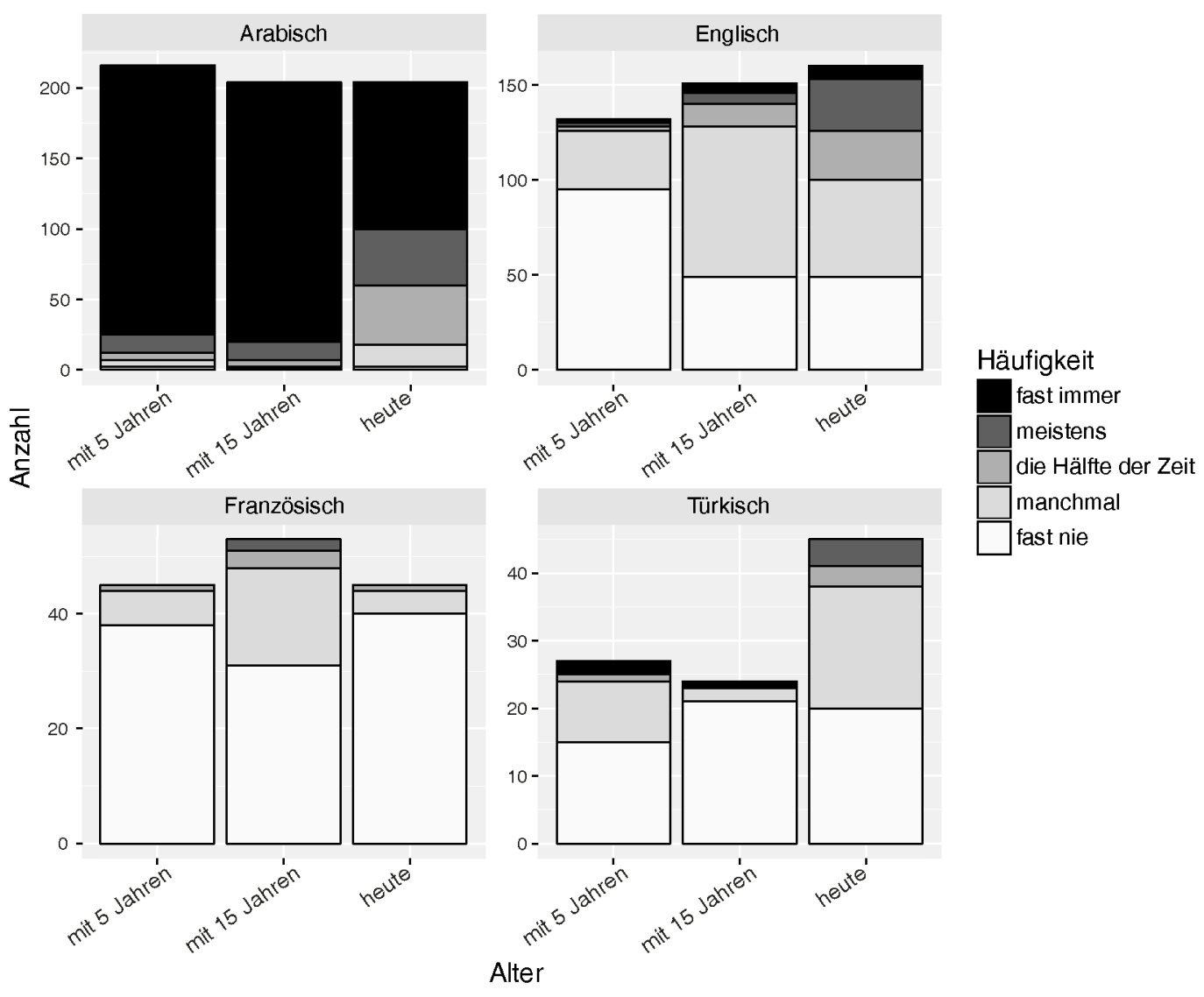

Abb. 12: Häufigkeitsverteilungen des Sprachgebrauchs des Arabischen, Englischen, Französischen und Türkischen in Kindheit, Jugend und zum Zeitpunkt der Erhebung

\subsubsection{Sprachbiografien: Geflïchtete aus Eritrea und dem Iran}

Mit nur 16 Teilnehmer/innen kommen nur wenige Geflüchtete im Datensatz aus Eritrea. Noch weniger stammen aus dem Iran (14 Befragte, davon 12 Geflüchtete). Dies lässt zwar keine stark belastbaren Aussagen zu diesen Herkunftsgruppen zu, es lassen sich aber gewisse Muster, die für die Geflüchteten aus Syrien deutlich geworden sind, auch für diese kleineren Gruppen bestätigen. Abbildung 13, unten, verdeutlicht die Verteilung für die Eritreer/innen. Wie bei den syrischen Geflüchteten spricht die Mehrheit eine Standardsprache, während es auch einige Angaben zu Minderheitensprachen gibt. 14 Sprecher/innen geben Tigrinya als Mutter- oder frühe Erstsprache an. Die Sprache wird mit Eintritt in die Schule für alle zur Pflicht. Demgegenüber geben zwei Sprecher die Minderheitensprache Blin als (weitere) Erstsprache an. Ein weiterer Teilnehmer gibt als Erstsprache das Amharische an, das auch Staatssprache von Äthiopien ist. Das Englische nimmt für fast alle Befragten aus Eritrea mit Eintritt ins Bildungssystem die Rolle der einzigen Fremdsprache in der Schule ein. Zehn von ihnen erwerben erste Englischkennt- 
nisse schon in der Grundschule, 15 lernen ab der weiterführenden Schule Englisch. Das Arabische nimmt für die Eritreer/innen eine Rolle ein, die sich fast parallel zum Türkischen für die Syrer/innen verhält: Es wird nicht in der Schule erworben, gewinnt im Beruf leicht an Bedeutung und wird auf der Flucht relevant. Acht der Befragten (50\%) geben an, in den Durchgangsländern Sudan und Libyen bei längeren Aufenthalten Arabischkenntnisse erworben zu haben. Die Flucht aus Eritrea erfolgt manchmal auch durch Äthiopien (siehe Abschn. 6.1.2), sodass der Anteil derer, die mit dem Amharischen in Kontakt kommen, bei der Flucht ebenfalls steigt.

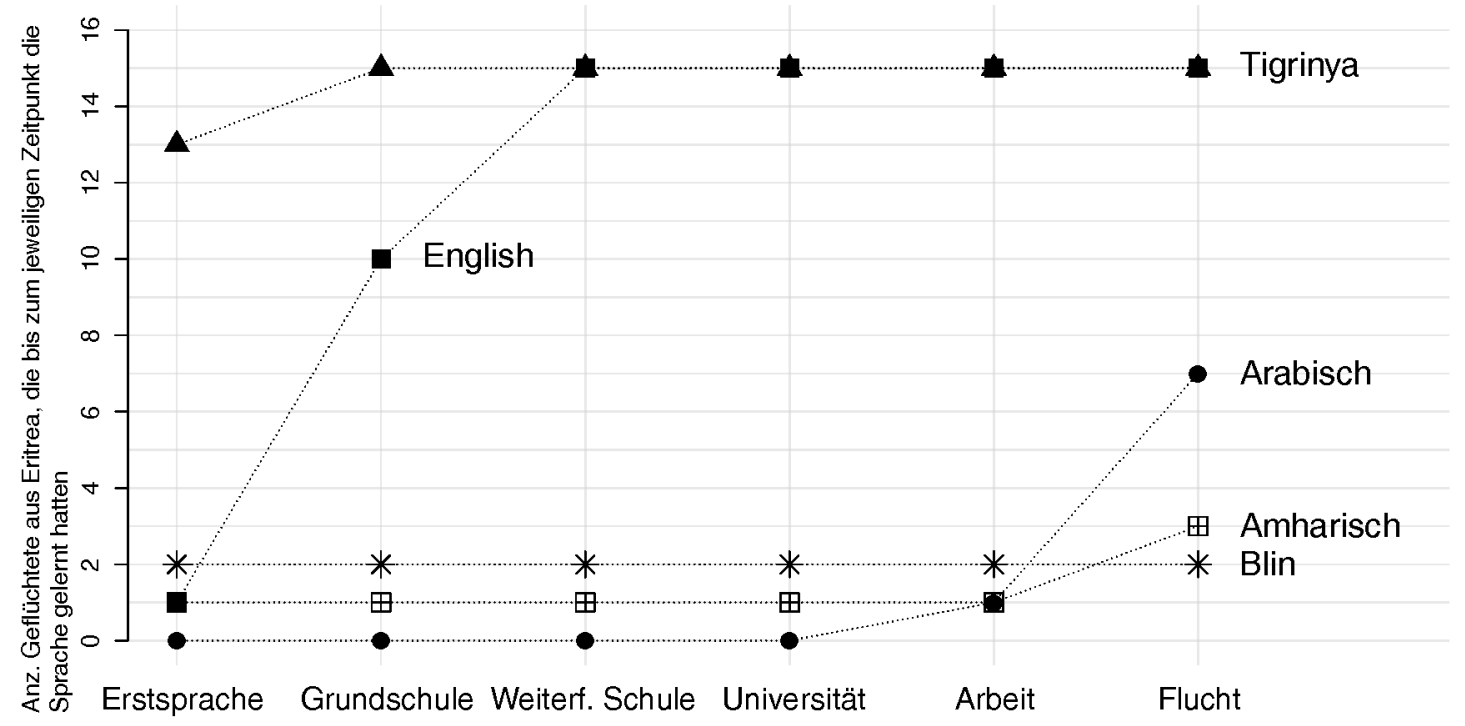

Abb. 13: Verlauf des Erwerbs der fünf häufigsten Sprachen bei den eritreischen Flüchtlingen

Bei den Geflüchteten aus dem Iran geben alle das Persische als Erstsprache an. Als zweite Erstsprachen werden die Minderheitensprachen Türkisch, Gilaki und das Aserbaidschan-Türkische genannt, das mit dem Türkischen eng verwandt ist. Auch das Arabische tritt einmal als Erstsprache auf. Das Englische wird in der weiterführenden Schule von fast allen iranischen Befragten gelernt. Mit Hocharabisch kamen fünf der Befragten in der Schule in Kontakt. Der multilinguale Sprecher des Gilaki erwirbt bei der Arbeit des Weiteren Japanisch. Weitere Sprachen treten nicht auf. Im Hinblick auf demografische Eigenheiten der aus dem Iran Geflüchteten ist es interessant zu erwähnen, dass die iranischen Teilnehmer/innen im Schnitt älter sind als die anderen Gruppen von Geflüchteten.

\subsubsection{Sprachbeherrschung}

Eine Feststellung der Kompetenz in allen angegeben Sprachen durch Tonaufnahmen hätte die Ziele unserer Umfrage in Umfang und Ambition weit überschritten. Die Erwartung unseres Teams war es nicht, verlässliche Daten über die Sprachbeherrschung in verschiedenen Fremdsprachen zu erhalten, sondern wichtige Trends bei der gefühlten Sprachbeherrschung abbilden zu können. Die Sprachkompetenzen in den angegebenen Fremdsprachen wurden deswegen durch die Befragten selbst eingeschätzt. Die Selbsteinschätzungen für die vier Fremdsprachen Englisch, Französisch, Türkisch und Arabisch (letzteres bei kurdischen Erstsprachlern), werden in Abbildung 14, unten, für die Geflüchteten aus Syrien dargestellt. Für die Eritreer ist die Anzahl der Angaben zu gering. Hervorgehoben werden in jeder Fremdsprache die Anzahl der Selbsteinschätzungen, die auf einer Likert- 
Skala von fünf Stufen als „sehr gut" oder „besonders gut" ausfielen ${ }^{12}$ - und zwar in den Kernkompetenzen „Lesen“, „Schreiben“, „Sprechen“ und „Verstehen“. In den „Schulsprachen" Englisch und Französisch fällt die Bewertung der schriftlichen Kompetenz höher aus als die der mündlichen Kompetenz. In den Funktionssprachen Türkisch und Arabisch hingegen ist das Verhältnis ausgeglichen, vermutlich weil die gesprochene Sprache hier eine größere Rolle spielt. Die wichtigste Erkenntnis aus der Darstellung ist jedoch die, dass nur wenige Geflüchtete angeben, wirklich solide Kompetenzen in den genannten Fremdsprachen zu haben. Arabisch bildet dabei eine Ausnahme, was auf die hohe Kompetenz der Kurden im Arabischen zurückzuführen ist. Zwar handelt es sich beim Arabischen für diese Sprecher um eine Fremdsprache, jedoch wird diese sehr früh in der Schule erworben und dominiert viele Lebensbereiche des Alltags. Dies führt zu Kernkompetenzen, die von allen als ,sehr gut“ oder ,besonders gut" eingeschätzt werden.

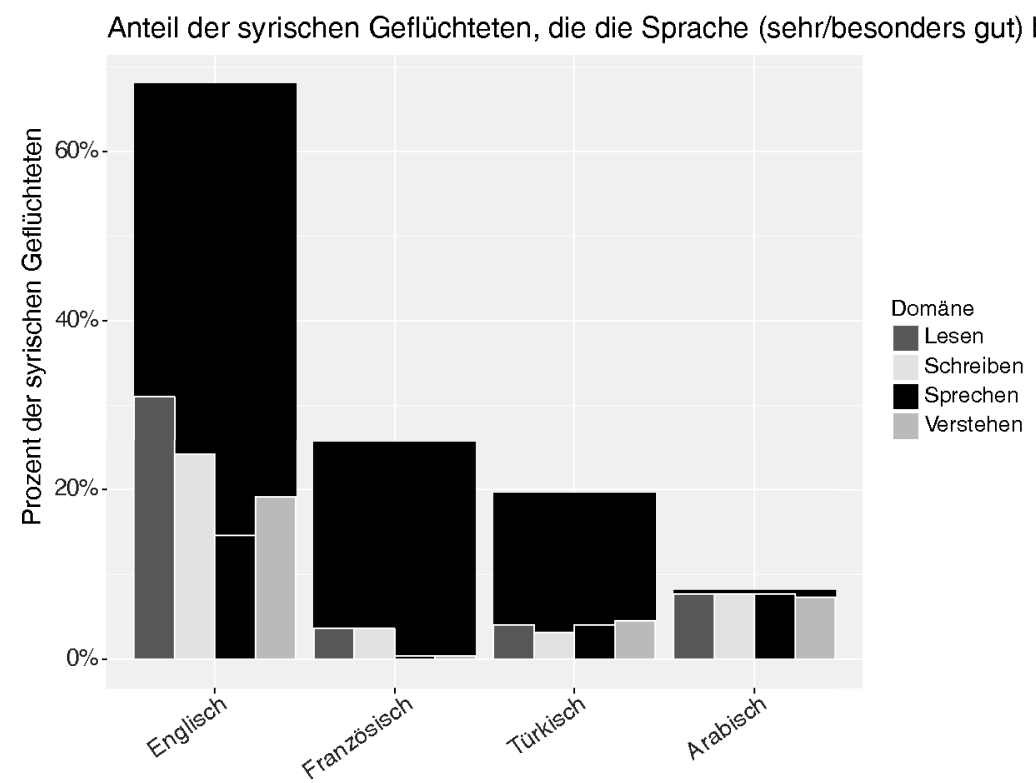

Abb. 14: Selbsteinschätzung der Geflüchteten in verschiedenen fremdsprachlichen Kompetenzdomänen

5.3 Wichtige Teilnehmergruppen unter den Geflüchteten in den Integrationskursen

Um mögliche Zusammenhänge zwischen den soziodemografischen Daten und den sprachbezogenen Angaben der Teilnehmenden noch näher zu untersuchen, setzten wir die Faktoren im Datensatz systematisch in Beziehung. Zu diesem Zweck führten wir eine Clusteranalyse durch. ${ }^{13}$ Bei dieser Methode werden die Merkmalsbündel aller Befragten verglichen und einander schrittweise nach minimaler Unähnlichkeit (technisch: Distanz) zugeordnet, bis sogenannte „Cluster“, also Ballungen von Befragten mit ähnlichen Merkmalskombinationen, entstehen. Die Faktoren unserer Analyse waren das Alter, die Anzahl der Bildungsjahre, die Anzahl der Jobs vor der Ankunft in Deutschland, die Länge des Aufenthalts in

12 Die Bewertung ,gut“ (ohne Attribut) wurde in den Likert-Skalen absichtlich nicht eingesetzt, weil der Begriff in verschiedenen Sprachen und Kulturkreisen unterschiedliche Werte darstellen kann, was zu Übersetzungsschwierigkeiten geführt hätte. „Gut" wurde daher immer mit einem Attribut wie ,nicht", „sehr" oder ,besonders" versehen.

13 Eine Einführung in die Methode für sprachwissenschaftliches Publikum findet sich bei Baayen (2008, S. 138f.). 
Deutschland sowie die Anzahl der Länder, in denen sich die Befragten vor der Ankunft in Deutschland aufhielten. In sprachlicher Hinsicht berücksichtigten wir die Anzahl der Erstsprachen als Kind, die Anzahl der Fremdsprachen in der Schule, die Anzahl der Sprachen im Berufsleben sowie die Gesamtanzahl der angegebenen Sprachen in der Umfrage. Aus diesen Werten wurden mit Hilfe verschiedener Cluster-Algorithmen („Ward“, „simple“, „complete“) sogenannte Dendrogramme errechnet. Dendrogramme sind aus der Verwandtschaftsforschung in der Biologie bekannt: Sie stellen die jeweilige Ähnlichkeit verschiedener Datenpunkte grafisch in Form eines umgedrehten Baumes dar. Je mehr Distanz zwischen den Ästen im Baum liegt ${ }^{14}$, desto unähnlicher sind sich die „Blätter“ (Endpunkte des Dendrogramms) und umgekehrt. Die Dendrogramme nach dem Algorithmus „Ward“, die der folgenden Ergebnispräsentation zu Grunde liegen, können unter dib.ids-mannheim.de in der Kategorie „Erhebung“ (Erste Erhebung) abgerufen werden.

Tabelle 3 enthält sieben Gruppen, die sich aus unserem Datensatz ergeben. Deutlich wird, dass sich die Gruppen zwar hauptsächlich im Hinblick auf die Kombination von Alter und Bildungsstand unterscheiden. Allerdings gibt es auch differenzierbare Eigenschaften im Hinblick auf die Arbeitserfahrung und die Mehrsprachigkeit, die die Unterschiede begründen. Der Altersdurchschnitt in den Gruppen A und B liegt bei ca. 34 Jahren. Im Hinblick auf ihren Bildungshintergrund unterscheiden sich die Gruppen deutlich. Die 19 Geflüchteten in Gruppe A haben im Durchschnitt um die acht Jahre im Bildungssystem verbracht, während die 33 Teilnehmer/innen in Gruppe B mit ca. 15 Jahren im Bildungssystem einen deutlich höheren Bildungsgrad aufweisen. In Gruppe A gibt es wenig Arbeitserfahrung, die auch vorwiegend in einfachen Berufen gesammelt wurde. In Gruppe B kann fast die Hälfte der Befragten auf Erfahrung in komplexen Berufen verweisen. In Gruppe A spielen weder frühe noch später erworbene Mehrsprachigkeit eine große Rolle. In Gruppe B findet sich Mehrsprachigkeit in fast allen Lebensphasen: es gibt multilinguale Muttersprachler/innen, mehr Schulfremdsprachen und mehr Fremdsprachen im Berufsleben.

Mit Teilnehmer/innen um die 26 Jahre ist Gruppe $\mathrm{C}$ jünger als die beiden vorangegangenen Gruppen. Auffällig ist hier auf den ersten Blick, dass die syrischen Geflüchteten weniger stark dominieren als in allen anderen Gruppen: neun von 24 Teilnehmer/innen haben einen eritreischen Hintergrund, zehn einen syrischen und fünf Personen kommen aus anderen Ländern. Alle Geflüchteten dieser Gruppe verweisen auf einen Aufenthalt in Deutschland von über einem Jahr. Es lassen sich aber auch andere Gemeinsamkeiten erkennen. Geringe Gestaltungsspielräume in Ländern wie Eritrea könnten zum Beispiel erklären, warum die Lebensläufe wenig Bildungsjahre, wenig Fremdsprachen in der Schule, aber durchgängig auch Berufserfahrung aufweisen - wenn auch mehrheitlich in einfachen Berufen. Die Gesamtzahl der im Leben erworbenen Sprachen ist in Gruppe C leicht höher als in der gut gebildeten, älteren Gruppe B (2.4 vs. 2.2 Sprachen).

Bei den 37 Mitgliedern der Gruppe D handelt es sich ebenfalls um Geflüchtete mit einem Altersdurchschnitt von 26 Jahren. Hier gibt es ähnlich wie in Gruppe A schwache Bildungshintergründe und wenig Arbeitserfahrung. Unter den Erstsprachen fällt hier eine Gruppe von sieben Sprechern mit kurdischer Muttersprache auf. Die Mehrsprachigkeit ist insgesamt aber etwas geringer ausgeprägt als in den Gruppen B und C, aber stärker als in Gruppe A. Ansonsten besteht eine starke Ähnlichkeit zu Gruppe A.

14 Dabei ist zu beachten, dass die Distanz über die Traversierung der „Äste“ des Baums von einem „Blatt“ zum anderen konzeptualisiert ist und nicht über die horizontale Distanz der „Blätter“. 
Die größte Gruppe von 65 Geflüchteten ist gleichzeitig die jüngste: die Teilnehmer/innen in Gruppe E sind zwischen 18 und 26 Jahre alt. Trotz des geringen Alters haben sie im Durchschnitt mehr Zeit im Bildungssystem verbracht als die 56 Geflüchteten in den Gruppen A und D, aber auch als die Geflüchteten in Gruppe C. Ungefähr die Hälfte hat immerhin einen Sekundarabschluss. Im Hinblick auf die Mehrsprachigkeit ist E die Spitzengruppe. Es gibt mehrere Angaben zu bilingualem und sogar trilingualem Erstspracherwerb. Zwölf dieser Angaben stammen von Sprecher/innen des Kurdischen. Über 30 der Geflüchteten in dieser Gruppe geben an, in der Schule mehr als nur eine Fremdsprache gelernt zu haben. Gleichzeitig haben aber 17 Personen in dieser Gruppe in der Schule keine Fremdsprache gelernt. Interessant ist auch, dass es 38 Personen mit Arbeitserfahrung gibt, von denen 12 auf der Arbeit auch mehr als eine Sprache verwendet haben. Insgesamt ergibt sich für Gruppe E die höchste Gesamtanzahl an erworbenen und erlernten Sprachen im Sample (Durchschnitt: 2.5).

Jung (im Schnitt 25 Jahre), gebildet und arbeitserfahren - oft in komplexen Jobs. So könnte man Gruppe F mit 60 Personen umschreiben. Es besteht eine starke Ähnlichkeit zu Gruppe B. Die Personen in Gruppe F sind allerdings nicht automatisch mehrsprachig. Nur 12 erlernen mehr als eine Erstsprache, die weiteren Sprachen erwarben sie während des Bildungswegs. Auch in der Selbstbewertung der Sprachkenntnisse ist Gruppe F selbstkritischer als die ältere, ebenfalls bildungsstarke Gruppe B, in der native Mehrsprachigkeit im Verhältnis häufiger auftritt.

Gruppe $\mathrm{G}$, die letzte relevante Gruppe in unserer Analyse, unterscheidet sich maßgeblich von den anderen Gruppen durch ihr hohes Alter. Die 48 Personen in der Gruppe sind mehrheitlich über 40 Jahre alt, der Altersdurchschnitt liegt bei 47 Jahren. Manche sind schon etwas länger in Deutschland als die jüngeren Geflüchteten anderer Gruppen. Die Personen in Gruppe G besitzen mittlere Bildungsabschlüsse (ca. 13 Jahre) und haben Arbeitserfahrung gemacht - auch in komplexen Berufen. Im Gegensatz zu Gruppe F mit den jungen Geflüchteten liegt der Grund hier eher in den längeren Lebensläufen. Im Hinblick auf die Sprachen verhält es sich ähnlich wie in Gruppe F oder Gruppe D: Die Personen sind eher monolingual aufgewachsen und erwerben im Verlauf des Lebens weniger Sprachen als die Befragten in Gruppen B, C, oder E. Bei der Selbstbewertung der Produktion der erworbenen Sprachen ist Gruppe G ebenfalls eher selbstkritisch.

\begin{tabular}{|c|c|c|c|c|c|}
\hline Gruppe & $\mathbf{n}$ & Alter & Bildung und Beruf & Mehrsprachigkeit & Sonstiges \\
\hline A & 19 & $\begin{array}{l}31-38 \mathrm{~J} \text {; } \\
\varnothing 34 \mathrm{~J} .\end{array}$ & $\begin{array}{l}\text { Kurzer Schulbesuch ( } \varnothing 8 \mathrm{~J} . \text { ), } \\
\text { wenig Arbeitserfahrung, die sich auf } \\
\text { einfache Berufe beschränkt }\end{array}$ & wenig ausgeprägt & $\begin{array}{l}2 \text { kurdische } \\
\text { Muttersprach- } \\
\text { ler/innen }\end{array}$ \\
\hline B & 33 & $\begin{array}{l}29-40 \mathrm{~J} . \\
\emptyset 34 \mathrm{~J} .\end{array}$ & $\begin{array}{l}\text { Lange Bildungskarrieren ( } \varnothing 15 \mathrm{~J} .) \text {, } \\
\text { berufserfahren auch in komplexen } \\
\text { Berufen }\end{array}$ & ausgeprägt & $\begin{array}{l}5 \text { kurdische } \\
\text { Muttersprach- } \\
\text { ler/innen }\end{array}$ \\
\hline $\mathrm{C}$ & 24 & $\begin{array}{l}16-36 \mathrm{~J} \text {; } \\
\varnothing 26 \mathrm{~J} .\end{array}$ & $\begin{array}{l}\text { Bildung beschränkt sich oft auf } \\
\text { Schulbesuch (Ø } 10 \mathrm{~J} .) \text {, aber es gibt } \\
\text { Berufserfahrung in einfachen, } \\
\text { manchmal in komplexen Berufen }\end{array}$ & $\begin{array}{l}\text { ausgeprägter unge- } \\
\text { steuerter Erwerb, } \\
\text { wenig Schulfremd- } \\
\text { sprachen }\end{array}$ & $\begin{array}{l}\text { Hälfte aller TN } \\
\text { aus Eritrea; alle } \\
\text { TN }>1 \text { Jahr } \\
\text { Aufenthalt in Dtl }\end{array}$ \\
\hline $\mathrm{D}$ & 37 & $\begin{array}{l}20-30 \mathrm{~J} . ; \\
\varnothing 26 \mathrm{~J} .\end{array}$ & $\begin{array}{l}\text { Sehr kurzer Schulbesuch (Ø } 7 \mathrm{~J} . \text { ), } \\
\text { wenig Arbeitserfahrung, einfache } \\
\text { Berufe }\end{array}$ & wenig ausgeprägt & $\begin{array}{l}7 \text { kurdische } \\
\text { Muttersprach- } \\
\text { ler/innen }\end{array}$ \\
\hline $\mathrm{E}$ & 65 & $\begin{array}{l}18-26 \mathrm{~J} . \\
\varnothing 22 \mathrm{~J} .\end{array}$ & $\begin{array}{l}\text { Junge Menschen mit Sekundarschul- } \\
\text { abschlüssen (Ø } 12 \mathrm{~J} \text {.), oft zu jung für } \\
\text { Arbeitserfahrung, oft einfache Berufe }\end{array}$ & sehr ausgeprägt & $\begin{array}{l}12 \text { kurdische } \\
\text { Muttersprach- } \\
\text { ler/innen }\end{array}$ \\
\hline
\end{tabular}




\begin{tabular}{|l|l|l|l|l|l|}
\hline Gruppe & $\mathbf{n}$ & Alter & Bildung und Beruf & Mehrsprachigkeit & Sonstiges \\
\hline F & 60 & $\begin{array}{l}\text { 20-29 J.; } \\
\varnothing 26 \mathrm{~J} .\end{array}$ & $\begin{array}{l}\text { Lange Bildungskarrieren (Ø 15 J.), } \\
\text { berufserfahren auch in komplexen } \\
\text { Berufen }\end{array}$ & $\begin{array}{l}\text { wenig ausgeprägt, } \\
\text { trotz hohem } \\
\text { Bildungsgrad }\end{array}$ & $\begin{array}{l}6 \text { kurdische } \\
\text { Muttersprach- } \\
\text { ler/innen }\end{array}$ \\
\hline G & 48 & $\begin{array}{l}38-60 \mathrm{~J} . ; \\
\varnothing 47 \mathrm{~J} .\end{array}$ & $\begin{array}{l}\text { Sekundarschulabschlüsse }(\varnothing 13 \mathrm{~J} .), \\
\text { Hinweise auf altersbedingten beruf- } \\
\text { lichen Aufstieg, berufserfahren in } \\
\text { mehreren Jobs, auch in komplexen } \\
\text { Berufen }\end{array}$ & $\begin{array}{l}\text { wenig ausgeprägt, } \\
\text { trotz mittlerem } \\
\text { Bildungsgrad und } \\
\text { Arbeitserfahrung }\end{array}$ & $\begin{array}{l}\text { 2 kurdische } \\
\text { Muttersprach- } \\
\text { ler/innen, 12 TN } \\
\text { seit > 1 Jahr in } \\
\text { Dtl. }\end{array}$ \\
\hline
\end{tabular}

Tab. 3: Übersicht über fünf typische Gruppen von Geflüchteten, die derzeit am Integrationskurs teilnehmen

Der Überblick aller beschriebenen Gruppen zeigt, dass es sich bei den Geflüchteten im Hinblick auf die sprachlich-demografischen Hintergründe keinesfalls um eine homogene Gruppe handelt. Vielmehr ist die Lage komplex. Zwar stützt sich die Gruppenbildung stark auf die Faktoren „Alter“ und „Bildungsjahre“, aber es gibt spezielle Eigenschaften im Hinblick auf die Bildungsabschlüsse, Berufsarten, Herkunftsländer und die Mehrsprachigkeit, die die Gruppen darüber hinaus charakterisieren. Bildungsverläufe und Arbeitserfahrung ergänzen sich oft zu einem sinnvollen Gesamtbild. Den Gruppen C und E mangelt es vor allem deswegen an langen Bildungskarrieren und Arbeitserfahrung, weil die sozialen Rahmenbedingungen bzw. das Alter dem entgegenstehen. Größere Sprachrepertoires sind zudem nicht automatisch in bildungsstarken oder berufserfahrenen Gruppen zu finden, denn die Befragten in den Gruppen $\mathrm{C}$ und $\mathrm{E}$ verweisen auf mehrere ungesteuert erworbene Fremdsprachen. Demnach sollte Mehrsprachigkeit für manche Gruppen als Ressource auf dem Weg zu einer besseren Ausgangsposition verstanden werden.

Gruppe E ist auch auf andere Art interessant: Hier finden sich die meisten Angaben zum Kurdischen als Erstsprache. In den Gruppen D und E, also den weniger gebildeten und wenig arbeitserfahrenen jüngeren Gruppen, ist Kurdisch für ein Fünftel aller Befragten die Muttersprache. Dies könnte mit dem Phänomen der „verschwiegenen Sprachen“ zu tun haben, das Brizić (2007) beschreibt und bei dem prekäre Verhältnisse eng mit nativer Mehrsprachigkeit und sprachlichen Repressionen verbunden sind. Die restriktive Sprachpolitik in Syrien gegenüber der kurdischen Bevölkerung ist seit Langem bekannt. ${ }^{15}$

Im Folgenden wenden wir uns dem Deutschen als der Sprache zu, die für fast niemanden unter den Befragten vor der Flucht relevant war, die aber in ihrer aktuellen Situation maßgeblich an Bedeutung gewinnt.

\subsection{Der Spracherwerb des Deutschen und die soziale Situation in Deutschland}

Im Kontext der Einwanderung ist der Erwerb des Deutschen eng mit der sozialen Situation verbunden, wie quantitative Studien zum ungesteuerten Spracherwerb unter Gastarbeitern in der Vergangenheit gezeigt haben (siehe Abschn. 2). Mit einer Reihe von Fragen nahmen wir daher die soziale Lage der Geflüchteten in Deutschland in den Blick, die ja im Gegensatz zu den genannten Gastarbeitern in einem gesteuerten Prozess die deutsche Sprache erwerben. Insbesondere die Arbeitssituation, das Engagement in Vereinen oder Freizeitgruppen sowie die allgemeinere Frage, ob die Geflüchteten zum Zeitpunkt des Kurses deutschsprachige Bekannte oder Freunde hatten, schienen uns relevant. Dabei stellte sich heraus, dass nur ein kleiner Teil $(n=21,7 \%)$ der Befragten zum ersten Erhebungszeitpunkt

15 So zum Beispiel in einem Bericht von Human Rights Watch (1996): www.hrw.org/reports/1996/ Syria.htm (Stand: 16.5.2018). 
bereits in Deutschland gearbeitet hat, was u.a. der rechtlichen Situation geschuldet sein dürfte. In Vereinen oder anderen Gruppen sind ähnlich wenige Geflüchtete organisiert $(n=28,9,3 \%)$, der Großteil davon in Sportvereinen $(n=17)$. Deutlich über die Hälfte $(58,1 \%)$ der Geflüchteten gab jedoch an, dass sie deutschsprachige Bekannte oder Freunde hätten. Die Mehrzahl davon (61,1\%) gab an, zum Zeitpunkt der Erhebung „weniger als 5“, etwa ein Viertel „5 bis 10“ Bekannte oder Freunde zu haben. Der Rest nannte eine höhere Zahl. Wir können außerdem auf detailliertere Fragen hinsichtlich der Frequenz von Treffen und der Verwendung des Deutschen zurückgreifen. Die meisten Geflüchteten mit deutschsprachigen Bekannten $(63,4 \%)$ treffen diese wöchentlich bzw. alle zwei Wochen. 20\% treffen sich monatlich oder seltener. 16,6\% treffen sich täglich mit ihren deutschsprachigen Bekannten. Nehmen wir die Verwendung der deutschen Sprache mit ins Bild, zeigt sich, dass immerhin 58 der befragten Geflüchteten (19\%) ihre Bekannten mindestens wöchentlich treffen und dabei meistens oder immer Deutsch mit ihnen sprechen. Unter dem Gesichtspunkt der sozialen Interaktion mit der deutschsprachigen Bevölkerung und dem Einsatz der neuen Sprache haben insbesondere diese Personen eine gute Ausgangsposition.

Es liegt nahe, die soziale Integration (hier operationalisiert über die Selbstauskunft zu deutschsprachigen Bekannten und Freunden) mit der Einschätzung der eigenen Deutschexpertise in Verbindung zu bringen. Oder als Frage formuliert: Schätzen die Geflüchteten ihre Deutschkenntnisse besser ein, wenn sie mehr Kontakt zur deutschsprachigen Bevölkerung haben?

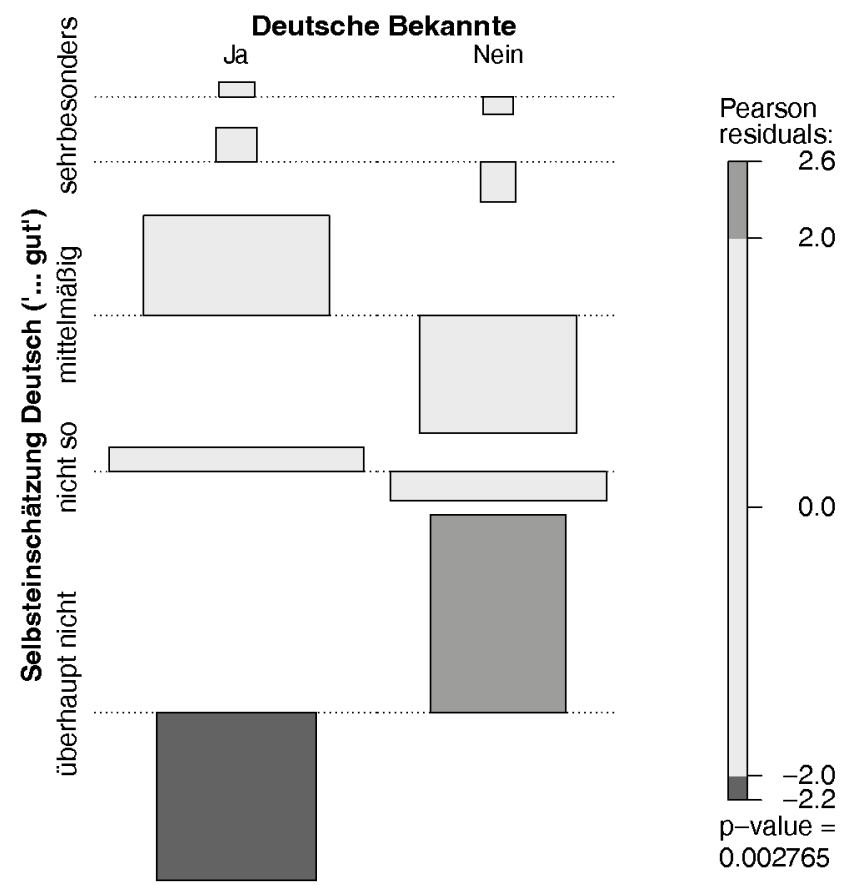

\begin{abstract}
Abb. 15: Zusammenhang zwischen dem Vorhandensein deutschsprachiger Bekannter (linke Spalte: ja; rechte Spalte: nein) und der Selbsteinschätzung der Deutschexpertise (von unten nach oben: überhaupt nicht gut, nicht so gut, mittelmäßig gut, sehr gut, besonders gut). Eingefärbte Flächen zeigen eine signifikante Abweichung der beobachteten Häufigkeit von der erwarteten Häufigkeit. Balken, die von der Grundlinie nach oben zeigen, zeigen eine signifikante Abweichung nach oben an (rechte Spalte: unterer Balken). Dementsprechend zeigt ein Balken, der von der Grundlinie nach unten reicht, eine signifikante Abweichung nach unten an (linke Spalte: unterer Balken).
\end{abstract}

Ein Chi-Quadrat-Test legt eine etwas komplexere Interpretation des Zusammenhangs nahe. Zwar antworten jene Befragten, die deutsche Bekannte haben (in Abb. 15 in der linken Spalte), proportional häufiger, dass sie Deutsch „mittelmäßig“, „sehr gut" oder „besonders

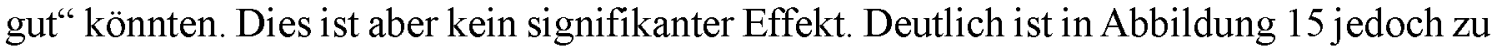
sehen, dass jene Geflüchtete mit deutschsprachigen Bekannten proportional deutlich seltener angeben, dass sie Deutsch „überhaupt nicht gut" könnten. Auf der Gegenseite, also jenen, die keine deutschsprachigen Bekannten haben (in Abb. 15 in der rechten Spalte), wird dagegen signifikant häufiger angegeben, dass sie Deutsch „überhaupt nicht gut" könn- 
ten. Diese Daten legen nahe, dass sich jene Geflüchteten, die Kontakt mit der deutschsprachigen Bevölkerung pflegen, deutlich weniger ,verloren“ fühlen, wenn es um die für sie neue Sprache geht. Dies gilt insbesondere, wenn man sie mit jenen Befragten vergleicht, die nicht die Chance haben, sich durch soziale Kontakte etwas sicherer in ihren Deutschkenntnissen zu fühlen. Diese Beobachtung können wir mit einem Gruppenvergleich untermauern (Mann-Whitney U-Test): Jene Befragten, die angaben, dass sie deutschsprachige Bekannte hätten, schätzen ihre Deutschkenntnisse auf der 5-stufigen Bewertungsskala signifikant $(p=0,0002)$ höher ein - wenn auch insgesamt auf eher geringem Niveau.

In der zweiten Erhebungswelle zum Ende des Kurses (Modul 6) stellten wir den Teilnehmer/innen die Frage, ob sie inzwischen neue deutsche Freunde oder Bekannte haben. Unter den 257 Befragten, die auch an der ersten Erhebung teilgenommen hatten, befanden sich noch 144 Geflüchtete. Von diesen hatten in der Zeit zwischen den beiden Erhebungen $64(45,4 \%)$ neue deutsche Freunde oder Bekannte kennengelernt. 16 dieser Teilnehmenden hatten zuvor angegeben, noch keine deutschsprachigen Bekannten zu haben. 40 Geflüchtete $(28,4 \%)$, die zum ersten Erhebungszeitpunkt angegeben hatten, keine deutschsprachigen Bekannten zu haben, haben auch während der Zeit des Integrationskurses keine deutschen Freunde oder Bekannten gefunden.

Unabhängig vom Vorhandensein deutschsprachiger Bekannter ist, was die Einschätzung der eigenen Sprachfähigkeiten angeht, ein leichter aber höchst signifikanter $(p<0,0001)$ Anstieg zu verzeichnen: Gemessen in Skalenpunkten, zeigt ein Mann-Whitney U-Test einen Anstieg von ca. einem Punkt auf der 5-stufigen Selbstbewertungsskala (von hauptsächlich „nicht so gut“ zu hauptsächlich ,mittelmäßig gut"). Interessanterweise ist dieser Anstieg im letzten Modul des Integrationskurses nicht davon abhängig, ob die Befragten deutschsprachige Bekannte hatten oder hinzugewonnen haben.

Mit einer weiteren Frage der zweiten Erhebung erkundigten wir uns nach der Einschätzung der Befragten, wie „sich Ihr Leben in Deutschland in den nächsten Jahren entwickelt“. Da die überwiegende Mehrheit der befragten Geflüchteten hier positiv in die Zukunft blickt (Antwortoptionen ,sehr gut" und „eher gut": 84,8\%), lassen sich schwer aussagekräftige Werte gewinnen, da ein sog. Deckeneffekt vorliegt (d.h. es liegen so viele positive Werte vor, dass zwischen positiven und negativen Werten nicht mehr sinnvoll differenziert werden kann). Qualitativ zeigt sich aber, dass fast alle Personen, die neutral oder negativ in die Zukunft blicken, ihre Deutschexpertise eher schlechter einschätzen und mehrheitlich (jedoch nur 11 zu 9) keine neuen deutschen Bekannten gefunden haben.

Aus den Befunden lässt sich keine stringente kausale Kette der verschiedenen sozialen Faktoren ableiten. Ein Modell, das beispielsweise annähme, dass bessere soziale Integration zu besserer Sprachexpertise führt, welche wiederum optimistischer in die Zukunft blicken lässt, ist sicherlich zu einfach. Vielmehr haben wir es hier mit einem komplexen Wirkungszusammenhang zu tun, in dem sich soziale Integration, Deutschexpertise, Optimismus und weitere Faktoren, die wir hier nicht betrachtet haben (Ereignisse im Heimatland, Verlauf des Asylverfahrens, Kriegstraumata etc.), gegenseitig bedingen. Unsere Studie kann aber zumindest erste Hinweise auf mögliche Zusammenhänge liefern.

\section{Vergleich mit früheren Studien}

Der zweite Abschnitt unseres Beitrags fasst drei Studien zusammen, die in vergangenen Jahren im Namen des BAMF in den Integrationskursen oder mit Unterstützung des BAMF (IAB-BAMF-SOEP-Befragung) unter Geflüchteten durchgeführt wurden. In Tabelle 4, 
unten, vergleichen wir Ziele, Methoden und einige wichtige soziodemografische Eckdaten dieser Studien mit den Daten der ersten IDS-Goethe-Erhebung (alle 606 Teilnehmer/innen). Es wird deutlich, dass sich die Zusammensetzung der IKs in Richtung der Population der Geflüchteten verändert. Die BAMF-Studien der Jahre 2011 und 2006 unterscheiden sich an einigen Stellen stark von den Ergebnissen der IAB-BAMF-SOEP-Befragung von Geflüchteten, und die IDS-Goethe-Studie weist Merkmale auf, die als Ergebnis der zu erwartenden Entwicklung verstanden werden können. So ist zum Beispiel vom Integrationspanel zur IDS-Goethe-Studie eine deutliche Verschiebung hin zu den männlichen Befragten zu sehen (von 37\% vs. 61\%). Das Durchschnittsalter fällt leicht. Ein großer Teil der IDS-GoetheDaten kam von syrischen Teilnehmer/innen (37\%). Fast niemand von den Kursteilnehmer/innen kommt heute aus den GUS-Staaten (2\%). Politische Entwicklungen, die nichts mit der Fluchtmigration zu tun haben, führen dazu, dass heute auch mehr Personen aus EU-Ländern in den IKs sitzen (8\% Integrationspanel vs. 21\% IDS-Goethe). Die Befragten im IK waren bei der IDS-Goethe-Studie seit kürzerer Zeit in Deutschland als es in den Jahren zuvor der Fall war. Die Zahl der Kursteilnehmer/innen mit Schulabschluss lag in der IDS-Goethe-Studie bei fast 100\%. Das ist vermutlich darauf zurückzuführen, dass seit mehreren Jahren differenziertere Angebote wie Alphabetisierungskurse und Zweitschriftkurse angeboten werden, sodass diese Lerner/innen (noch) nicht an den von uns untersuchten IKs teilnahmen. Die Zahl der Befragten mit Berufserfahrung im Ausland bleibt mit mehr als zwei Dritteln unverändert hoch. Interessant ist auch die soziale Situation in Deutschland im Vergleich: Das Engagement in Vereinen scheint in allen Studien eher gering, ist aber im Integrationspanel doppelt so hoch wie in der IDS-Goethe-Studie. Dafür haben ein Fünftel der Teilnehmer/innen der IDS-Goethe-Studie bei Kursbeginn bereits in Deutschland gearbeitet (Integrationspanel 12\%). Die deutschen Kontakte sind beim Integrationspanel mit einem Mittelwert „3“ angegeben, der ohne weitere Angaben schwer zu interpretieren ist. Er lässt aber annehmen, dass ca. die Hälfte der Teilnehmer/innen über deutschsprachige Kontakte verfügt. Über $60 \%$ der Geflüchteten in der IAB-BAMF-SOEPStudie geben sogar häufige Kontakte zu Deutschen an. Allerdings bleibt hier die Anzahl der Kontakte unklar. In der IDS-Goethe-Studie gleicht der Prozentwert der Kontakte dem der IAB-BAMF-SOEP-Studie. Allerdings sind es bei der Mehrheit aller Befragten nur wenige deutsche Bekanntschaften.

\begin{tabular}{|l|l|l|l|l|}
\hline & $\begin{array}{l}\text { Haug/Zerger } \\
\mathbf{( 2 0 0 6 ) :} \\
\text { Befragung 2005 }\end{array}$ & $\begin{array}{l}\text { Schuller/Lochner/ } \\
\text { Rother (2011): } \\
\text { Integrationspanel } \\
\mathbf{2 0 0 8}\end{array}$ & $\begin{array}{l}\text { Babka von } \\
\text { Gostomski et al. } \\
\mathbf{( 2 0 1 6 ) :} \\
\text { IAB-BAMF-SOEP- } \\
\text { Befragung von } \\
\text { Geflüchteten 2016 }\end{array}$ & $\begin{array}{l}\text { IDS-Goethe- } \\
\text { Studie (2018): } \\
\text { Erste Welle 2016 }\end{array}$ \\
\hline Ziel: & $\begin{array}{l}\text { Erfassung der } \\
\text { Teilnehmer/innen- } \\
\text { wünsche im IK }\end{array}$ & $\begin{array}{l}\text { Längsschnittstudie } \\
\text { des Integrations- } \\
\text { erfolges des IK }\end{array}$ & $\begin{array}{l}\text { Erfassung der } \\
\text { Situation von } \\
\text { Geflüchteten }\end{array}$ & $\begin{array}{l}\text { Erfassung der } \\
\text { Sprachhintergründe } \\
\text { im IK }\end{array}$ \\
\hline $\begin{array}{l}\text { Teilnehmer/ } \\
\text { innenzahl, An- } \\
\text { zahl der Kurse: }\end{array}$ & $\begin{array}{l}\text { 1.304 Kursteilneh- } \\
\text { mer/innen aus } \\
\text { 86 Kursen }\end{array}$ & $\begin{array}{l}\text { 2.094 Kursteilneh- } \\
\text { mer/innen aus } \\
\text { 253 Kursen }\end{array}$ & $\begin{array}{l}\text { 2.349 Geflüchtete } \\
\text { aus 1.766 Haushalten }\end{array}$ & $\begin{array}{l}\text { 606 Teilneh- } \\
\text { mer/innen aus } \\
\text { 42 Kursen }\end{array}$ \\
\hline $\begin{array}{l}\text { Erhebungs- } \\
\text { medium: }\end{array}$ & $\begin{array}{l}\text { Fragebögen auf } \\
\text { Papier }\end{array}$ & $\begin{array}{l}\text { Fragebögen auf } \\
\text { Papier }\end{array}$ & $\begin{array}{l}\text { Computergestützte } \\
\text { Interviews }\end{array}$ & $\begin{array}{l}\text { Tablets: App mit } \\
\text { Aufnahmefunktion }\end{array}$ \\
\hline $\begin{array}{l}\text { Übersetzung } \\
\text { und Nutzung } \\
\text { von Überset- } \\
\text { zungen: }\end{array}$ & $\begin{array}{l}\text { Russisch, Türkisch, } \\
\text { Englisch; Angebot } \\
\text { kaum genutzt }\end{array}$ & $\begin{array}{l}\text { Zur Orientierung } \\
\text { stand eine Überset- } \\
\text { zung in 13 Sprachen } \\
\text { zur Verfügung }\end{array}$ & $\begin{array}{l}\text { Alle Fragen in } \\
\text { 7 Sprachen sowohl } \\
\text { schriftlich als auch } \\
\text { mündlich }\end{array}$ & $\begin{array}{l}\text { Angebot in } \\
\text { 16 Sprachen, Nut- } \\
\text { zung fast aller } \\
\text { Angebote }\end{array}$ \\
\hline
\end{tabular}




\begin{tabular}{|c|c|c|c|c|}
\hline & $\begin{array}{l}\text { Haug/Zerger } \\
(2006) \text { : } \\
\text { Befragung } 2005\end{array}$ & $\begin{array}{l}\text { Schuller/Lochner/ } \\
\text { Rother (2011): } \\
\text { Integrationspanel } \\
2008\end{array}$ & $\begin{array}{l}\text { Babka von } \\
\text { Gostomski et al. } \\
\text { (2016): } \\
\text { IAB-BAMF-SOEP- } \\
\text { Befragung von } \\
\text { Geflüchteten } 2016\end{array}$ & $\begin{array}{l}\text { IDS-Goethe- } \\
\text { Studie (2018): } \\
\text { Erste Welle } 2016\end{array}$ \\
\hline $\begin{array}{l}\text { Altersvertei- } \\
\text { lung und } \\
\text { Geschlecht: }\end{array}$ & $\begin{array}{l}\text { Durchschnitts- } \\
\text { alter } 34 \\
45 \% \text { männl., } \\
55 \% \text { weibl. }\end{array}$ & $\begin{array}{l}\text { Durchschnitts- } \\
\text { alter } 35 \\
37 \% \text { männl., } \\
63 \% \text { weibl. }\end{array}$ & $\begin{array}{l}58 \% \text { sind } 30 \text { oder } \\
\text { jünger } \\
66 \% \text { männl., } \\
34 \% \text { weibl. }\end{array}$ & $\begin{array}{l}\text { Durchschnitts- } \\
\text { alter } 31 \\
61 \% \text { männl., } \\
38 \% \text { weibl. }\end{array}$ \\
\hline Herkunft: & $\begin{array}{l}\text { Über } 55 \% \text { GUS- } \\
\text { Staaten (potent. } \\
\text { Spätaussiedler/ } \\
\text { innen), } \\
11 \% \text { Türkei, } 5 \% \text { EU, } \\
25 \% \text { andere Länder }\end{array}$ & $\begin{array}{l}\text { Ca. } 32 \% \text { GUS-Staaten } \\
\text { (potent. Spätaussied- } \\
\text { ler/innen), } \\
17 \% \text { Türkei, } 8 \% \text { EU, } \\
41 \% \text { andere Länder }\end{array}$ & $\begin{array}{l}41,5 \% \text { Syrien, } \\
10 \% \text { Afghanistan, } \\
8 \% \text { Irak, } 6 \% \text { Balkan, } \\
7 \% \text { Eritrea/Somalia, } \\
28 \% \text { andere Länder }\end{array}$ & $\begin{array}{l}\text { Ca. } 2 \% \text { GUS- } \\
\text { Staaten }{ }^{16}, \\
2,3 \% \text { Türkei, } 21 \% \\
\text { EU, } 37 \% \text { Syrien, } \\
39 \% \text { andere Länder }\end{array}$ \\
\hline $\begin{array}{l}\text { Aufenthalts- } \\
\text { länge: }\end{array}$ & $\begin{array}{l}\text { Mittelwert: } \\
2.5 \text { Jahre } \\
(50 \%<1 \text { Jahr) }\end{array}$ & $\begin{array}{l}\text { Mittelwert: } \\
5 \text { Jahre } \\
(55,5 \%>2 \text { Jahre })\end{array}$ & $\begin{array}{l}\text { Reichweite: } \\
0-3 \text { Jahre (2013- } \\
\text { 2016) }\end{array}$ & $\begin{array}{l}\text { Mittelwert: } \\
\text { 1,4 Jahre } \\
\text { Reichweite: } \\
0 \text { bis } 26 \text { Jahre } \\
54 \%<1 \text { Jahr }\end{array}$ \\
\hline $\begin{array}{l}\text { Schul- } \\
\text { abschluss: }\end{array}$ & $81 \%$ Schulabschluss & $\begin{array}{l}84 \% \text { Schulabschluss } \\
\text { (46\% Hochschul- } \\
\text { zugang, 22\% weiter- } \\
\text { führende Schule) }\end{array}$ & $\begin{array}{l}84 \% \text { Schulbesuch } \\
\text { (37\% weiterführende } \\
\text { Schule) }\end{array}$ & $\begin{array}{l}\text { 99\% Schulbesuch } \\
\text { (44\% Hochschul- } \\
\text { zugang, 91\% wei- } \\
\text { terführende Schule) }\end{array}$ \\
\hline $\begin{array}{l}\text { Berufs- } \\
\text { erfahrung: }\end{array}$ & $82,4 \%$ & $71 \%$ & $73 \%$ & $76 \%$ \\
\hline $\begin{array}{l}\text { Deutsche } \\
\text { Kontakte: }\end{array}$ & Nicht erfasst & $\begin{array}{l}16 \% \text { sind in einem } \\
\text { Verein (nach } 3 . \text { Be- } \\
\text { fragung), } 12 \% \text { haben } \\
\text { in Dtl. gearbeitet } \\
\text { ( } 34 \% \text { arbeiten } 1 \text { Jahr } \\
\text { nach Kursende), An- } \\
\text { zahl der Teilnehmer } \\
\text { mit Kontakten unklar } \\
\text { (,Mittelwert } 3{ }^{\circ} \text { ) }\end{array}$ & $\begin{array}{l}\text { Keine Angabe zu } \\
\text { Vereinen, } 14 \% \text { in } \\
\text { Dtld. gearbeitet, } \\
60 \% \text { geben häufige } \\
\text { Kontakte zu Deut- } \\
\text { schen an }\end{array}$ & $\begin{array}{l}8 \% \text { sind in einem } \\
\text { Verein, } 21 \% \text { in } \\
\text { Dtld. gearbeitet, } \\
63 \% \text { geben deut- } \\
\text { sche Bekannte/ } \\
\text { Freunde an - aller- } \\
\text { dings mehrheitlich } \\
\text { „wenige“ }\end{array}$ \\
\hline
\end{tabular}

Tab. 4: Überblick über Ziele, Methoden und soziodemografische Eckdaten früherer IK-Studien und der IDS-Goethe-Studie

Im Hinblick auf das Hauptaugenmerk unserer Studie, die sprachlichen Hintergründe der Teilnehmenden, sind direkte Vergleiche aufgrund der unterschiedlichen Ausrichtung der Studien schwierig. Tabelle 5 dokumentiert einige erkennbare Veränderungen. Deutlich wird zum Beispiel, dass die Vielfalt der Erstsprachen stark zunimmt: die Hälfte der 606 Teilnehmenden an der IDS-Goethe-Studie sprechen 77 unterschiedliche Erstsprachen. In den Jahren davor lagen die „anderen Sprachen“ bei rund einem Drittel. In Abschnitt 5.2.1, oben, werden nur die Sprachen der Geflüchteten in der IDS-Goethe-Studie erfasst. Die tatsächliche Situation in den Integrationskursen, wo ehemalige Teilnehmergruppen und die Geflüchteten sich heute die Klassen teilen, ist viel komplexer.

16 Als GUS-Staaten wurden Kasachstan, Moldawien, Russland und die Ukraine (als teilnehmendes Mitglied) behandelt. Aus den anderen GUS-Staaten sind keine Teilnehmenden in der Stichprobe. 


\begin{tabular}{|c|c|c|c|c|}
\hline & $\begin{array}{l}\text { Haug/Zerger } \\
(2006) \text { : } \\
\text { Befragung } 2005\end{array}$ & $\begin{array}{l}\text { Schuller/Lochner/ } \\
\text { Rother (2011): } \\
\text { Integrationspanel } \\
2008\end{array}$ & $\begin{array}{l}\text { Babka von } \\
\text { Gostomski et al. } \\
\text { (2016): } \\
\text { IAB-BAMF-SOEP- } \\
\text { Befragung von } \\
\text { Geflüchteten } 2016\end{array}$ & $\begin{array}{l}\text { IDS-Goethe- } \\
\text { Studie (2018): } \\
\text { Erste Welle 2016 }\end{array}$ \\
\hline $\begin{array}{l}\text { Erstsprach- } \\
\text { erwerb: }\end{array}$ & Nicht erfasst & $\begin{array}{l}\text { Annahme: eine } \\
\text { Mutter-/Erstsprache } \\
\text { (29\% Russisch, } \\
\text { 14\% Türkisch, } \\
5 \% \text { Arabisch, } \\
5 \% \text { Polnisch, } \\
\text { 26\% andere Spra- } \\
\text { chen) }\end{array}$ & $\begin{array}{l}\text { Annahme: eine } \\
\text { Mutter-/Erstsprache } \\
\text { (44\% Arabisch, } \\
\text { 14\% Kurdisch, } \\
10 \% \text { Dari/Farsi, } \\
32 \% \text { andere Spra- } \\
\text { chen) }\end{array}$ & $\begin{array}{l}\text { Annahme Mehr- } \\
\text { sprachigkeit: } \\
69 \% \text { einsprachig; } \\
21 \% \text { zweisprachig; } \\
10 \% \text { drei- oder } \\
\text { mehrsprachig } \\
\text { (31\% Arabisch, } \\
10 \% \text { Englisch, } \\
6 \% \text { Kurdisch, } \\
6 \% \text { Rumänisch, } \\
47 \% 77 \text { Sprachen } \\
\text { unter } 5 \% \text { ) }\end{array}$ \\
\hline $\begin{array}{l}\text { Deutsch- } \\
\text { kenntnisse: }\end{array}$ & $\begin{array}{l}37 \% \text { Neuzugewan- } \\
\text { derte und } 14 \% \\
\text { Altzugewanderte } \\
\text { Deutschkenntnisse } \\
\text { zu Kursbeginn }\end{array}$ & $\begin{array}{l}\text { Selbsteinschätzung: } \\
69 \% \text { mündl. und } 73 \% \\
\text { schriftl. Deutsch- } \\
\text { kenntnisse; ,gut“ bis } \\
\text { „sehr gut": } 5 \%\end{array}$ & $\begin{array}{l}\text { Selbsteinschätzung } \\
\text { "mittel }{ }^{\circ}: 35 \%, \text { gut }^{\circ} \\
\text { bis ,,sehr gut": } 18 \%\end{array}$ & $\begin{array}{l}\text { Selbsteinschätzung: } \\
22 \% \text { mittelmäßig/ } \\
\text { sehr/besonders gut; } \\
2 \% \text { sehr/besonders } \\
\text { gut }\end{array}$ \\
\hline $\begin{array}{l}\text { Fremdspra- } \\
\text { chenkennt- } \\
\text { nisse und } \\
\text { Sprachkom- } \\
\text { petenz: }\end{array}$ & $\begin{array}{l}\text { Erfasst wurden bis } \\
\text { zu } 2 \text { weitere } \\
\text { gesprochene und } \\
\text { geschriebene } \\
\text { Sprachen, ausge- } \\
\text { wertet wurden nur } \\
\text { Alphabetisierungs- } \\
\text { sprachen. }\end{array}$ & $\begin{array}{l}61 \% \text { sprechen eine } \\
\text { weitere Sprache } \\
\text { mündl., } 25 \% \text { zwei } \\
\text { weitere Sprachen } \\
\text { mündl:; max. } 14 \\
\text { mündl. Sprachen }\end{array}$ & $\begin{array}{l}\text { Selbsteinschätzung: } \\
\text { 29\% können } \\
\text { Englisch „gut“ oder } \\
\text { „sehr gut“ lesen, } \\
\text { keine Angaben zu } \\
\text { weiteren Sprachen }\end{array}$ & $\begin{array}{l}\text { Selbsteinschätzung: } \\
30 \% \text { sprechen min- } \\
\text { destens eine Fremd- } \\
\text { sprache sehr oder } \\
\text { besonders gut; } 40 \% \\
\text { lesen mindestens } \\
\text { eine Fremdsprache } \\
\text { sehr oder besonders } \\
\text { gut }\end{array}$ \\
\hline
\end{tabular}

Tab. 5: Überblick über sprachliche Angaben früherer IK-Studien und der IDS-Goethe-Studie

Im Hinblick auf die Deutschkenntnisse der Kursteilnehmer/innen müssen die Ergebnisse kritisch hinterfragt werden. In der IAB-BAMF-SOEP-Befragung von Geflüchteten geben 53\% im Jahr 2016 an, „mittelmäßig“ bis „sehr gut" Deutsch sprechen zu können. Dies ist überraschend, weil zu diesem Zeitpunkt kaum Geflüchtete den Integrationskurs abgeschlossen hatten. Der Wert steht in starkem Gegensatz zur selbstkritischen Haltung der meisten Teilnehmer/innen in der IDS-Goethe-Studie, in der sich $20 \%$,mittelmäßig gute“ Deutschkenntnisse zuschreiben und nur $2 \%$,sehr gute“ oder „,besonders gute“ Deutschkenntnisse. Die Diskrepanz kann an der Integrationskursumgebung liegen, in der die Deutschkenntnisse ständig reflektiert werden und Sprachprobleme deutlicher zu Tage treten als im Alltag. Ein weiterer Grund für die niedrigeren Werte in der IDS-Goethe-Studie kann die Formulierung des mittleren Skalenwerts sein, der bei der Übersetzung in vielen Sprachen einen positiven Unterton hat und den wir im Deutschen mit „mittelmäßig gut“ wiedergeben.

Für die früheren BAMF-Studien liegen keine Selbstbewertungen in den Fremdsprachen vor. Die Selbstbewertungen der IAB-BAMF-SOEP-Befragung zu den Lesefähigkeiten im Englischen lassen sich grob mit der IDS-Goethe-Studie vergleichen. 29\% der Teilnehmer/ innen behaupten, Englisch gut oder sehr gut lesen zu können. In unserer Studie geben 30\% 
an, eine Fremdsprache „sehr gut“ oder „besonders gut“ sprechen zu können. 40\% der Sprecher/innen können diese Fremdsprache „sehr" oder „besonders gut" lesen. Für die meisten Teilnehmer/innen ist diese Fremdsprache das Englische.

\section{Zusammenfassung}

Für die syrischen Geflüchteten, die im Datensatz mit 219 Personen die Mehrheit stellen, vermitteln die Daten solide Einblicke in das Vorkommen und die Stellung der wichtigsten Sprachen in verschiedenen Lebensabschnitten. Für die eritreischen und iranischen Teilnehmer/innen sind die Ergebnisse nicht in dem Maße gesichert. Wir konnten jedoch Ähnlichkeiten zur syrischen Gruppe im Hinblick auf die Vorkommen von Minderheitensprachen sowie im Hinblick auf den Unterschied zwischen Schulfremdsprachen und Funktionssprachen für Arbeit und Flucht feststellen. Der Anteil der Muttersprachler/innen von Minderheitensprachen bewegt sich zum Beispiel in allen Gruppen um die 10\%. Wichtige Minderheitensprachen sind Kurmandschi (Kurdisch) für die Syrer/innen, Blin für die Eritreer/innen und Azeri (Aserbaidschan-Türkisch) für die Iraner/innen. Neben der Bedeutung der Schulfremdsprachen lässt sich eine interessante Rolle für Funktionssprachen im Erwerbsleben und auf der Flucht erkennen. Sie bleiben in gewissem Umfang auch in Deutschland relevant. Wichtige Funktionssprachen im Erwerbsleben und auf der Flucht sind das Türkische für Personen aus Syrien und teilweise auch für Personen aus dem Iran sowie das Arabische und Amharisch für die eritreischen Geflüchteten. Dies stimmt auch mit Angaben zu den Fluchtrouten überein. Die syrischen Angaben unterstreichen, dass Sprachbiografien dynamisch zu verstehen sind und mit Blick auf die Kompetenz nicht überinterpretiert werden dürfen. In verschiedenen Phasen sind verschiedene Sprachen relevant. Was den Wert der Schulfremdsprachen angeht, so ist bemerkenswert, dass sich nur eine kleine Anzahl von Sprecher/ innen „sehr gute“ oder „besonders gute“ Kompetenzen in einer von ihnen zuschreibt.

Dass die Integrationskurse derzeit vor großen Herausforderungen stehen, zeigt unser Vergleich zwischen den BAMF-Studien, der IAB-BAMF-SOEP-Befragung und der IDS-Goethe-Studie in Abschnitt 6. Die vorgelegten Einblicke in ein immer komplexeres Teilnehmerfeld regen zum Nachdenken über mehr Passgenauigkeit bei der Ausrichtung der Kurse an. Ein Ergebnis unserer Arbeit, das dazu beitragen kann, ist die Identifikation von Teilnehmergruppen von Geflüchteten in den IKs, die bestimmte relevante soziodemografische und linguistische Merkmale teilen. Mit Hilfe einer Clusteranalyse konnten wir sieben unterscheidbare Gruppen von Geflüchteten in den IKs unterscheiden. Diese Gruppen sollten nicht als einheitliche Typen verstanden werden, sondern als heterogene Gruppen mit wichtigen Gemeinsamkeiten. Ein solcher Überblick kann für die pädagogische Ausrichtung zukünftiger Integrationskurse von Interesse sein. Derzeit werden neue Kurstypen oft nach Kriterien wie Geschlecht und Familiensituation konzipiert. Denkbar wären auch Kurse, die das Alter sowie unterschiedliche Bildungs- und Sprachbiografien berücksichtigen. Aus diesem Grund wäre eine ähnliche Analyse aller Kursteilnehmenden - also auch der ohne Fluchterfahrung - wichtig und sinnvoll. Eine entsprechende Analyse ist bereits in Bearbeitung und wird zeitgleich zu dieser Publikation den zahlreichen pädagogischen Kräften, Kursträgern, aber auch dem Bundesamt für Migration und Flüchtlinge zugänglich gemacht werden.

\section{Literatur}

Adamzik, Kirsten/Roos, Eva (Hg.) (2002): Biografie linguistiche/Biographies langières/Biographias linguisticas/Sprachbiographien. Neuchâtel: Inst. de Linguistique de 1'Univ. (= Builetin Suisse de Linguistique Appliquée 76). 
Auer, Peter (1999): From codeswitching via language mixing to fused lects. Toward a dynamic typology of bilingual speech. In: International Journal of Bilingualism, 3, 4. S. 309-32.

Auer, Peter (2013): Ethnische Marker im Deutschen zwischen Varietät und Stil. In: Deppermann, Arnulf (Hg.): Das Deutsch der Migranten. Berlin/New York: De Gruyter. S. 9-40. (= Jahrbuch des Instituts für Deutsche Sprache 2012).

Baayen, R. Harald (2008): Analyzing linguistic data. A practical introduction to statistics using R. Cambridge, UK: Cambridge University Press.

Babka von Gostomski, Christian et al. (2016): IAB-BAMF-SOEP-Befragung von Geflüchteten: Überblick und erste Ergebnisse. (= IAB-Forschungsbericht 14). Online unter: http://doku.iab.de/forschungsbericht/ 2016/fb 1416.pdf (Stand 18.6.2018).

Blommaert, Jan (2010): The sociolinguistics of globalization. Cambridge, UK: Cambridge University Press.

Blommaert, Jan (2013): Ethnography, superdiversity and linguistic landscapes. Chronicles of complexity. Bristol u.a.: Multilingual Matters.

Brizić, Katharina (2007): Das geheime Leben der Sprachen. Gesprochene und verschwiegene Sprachen und ihr Einfluss auf den Spracherwerb in der Migration. Münster u.a.: Waxmann.

Bundesagentur für Arbeit (2011): Klassifikation der Berufe 2010 - Band 1: Systematischer und alphabetischer Teil mit Erläuterungen. Online unter: https://statistik.arbeitsagentur.de/Statischer-Content/Grund lagen/Klassifikation-der-Berufe/KldB2010/Printausgabe-KldB-2010/Generische-Publikationen/KldB2010Printversion-Band1.pdf (Stand: 7.6.2018).

Bundesamt für Migration und Flüchtlinge (Hg.) (2017): Grafische Übersicht zum Integrationskurs. Online unter: www.bamf.de/SharedDocs/Anlagen/DE/Publikationen/Plakate/grafische-uebersicht-integrations kurs.pdf (Stand: 28.2.2018).

Busch, Brigitta (2010): Die Macht präbabylonischer Phantasien. Ressourcenorientiertes sprachbiographisches Arbeiten. In: Zeitschrift für Literaturwissenschaft und Linguistik 160. S. 58-82.

Chlosta, Christoph/Ostermann, Torsten (2005): Sprachenvielfalt in der Grundschule. In: Bartitzky, Horst/ Speck-Hamdan, Angelika (Hg.): Deutsch als Zweitsprache lernen. Frankfurt a.M.: Grundschulverband Arbeitskreis Grundschule e.V. S. 33-43. (= Beiträge zur Reform der Grundschule, 120).

Cindark, Ibrahim (2010): Migration, Sprache und Rassismus. Der kommunikative Sozialstil der Mannheimer „Unmündigen“ als Fallstudie für die „emanzipatorischen Migranten“. Tübingen: Narr. (= Studien zur Deutschen Sprache 51).

Cindark, Ibrahim (2013): Deutsch-türkisches Code-Switching und Code-Mixing. In: Deppermann, Arnulf (Hg.): Das Deutsch der Migranten. Berlin: De Gruyter. S. 9-40. (= Jahrbuch des Instituts für Deutsche Sprache 2012).

Cindark, Ibrahim/Ziegler, Evelyn (2016): Mehrsprachigkeit im Ruhrgebiet. Zur Sichtbarkeit sprachlicher Diversität in Dortmund. In: Ptashnyk, Stefaniya et al. (Hg.): Gegenwärtige Sprachkontakte im Kontext der Migration. Heidelberg: Winter. S. 133-156.

Clahsen, Harald/Meisel, Jürgen/Pienemann, Manfred (1983): Deutsch als Zweitsprache: der Spracherwerb ausländischer Arbeiter. Tübingen: Narr. (= Tübinger Beiträge zur Linguistik 3).

Clyne, Michael (2000): Lingua Franca and Ethnolects in Europe and Beyond. In: Sociolinguistica 14. S. 83-89.

Deppermann, Arnulf (2000): Ethnographische Gesprächsanalyse: Zu Nutzen und Notwendigkeit von Ethnographie für die Konversationsanalyse. In: Gesprächsforschung - Online-Zeitschrift zur verbalen Interaktion 1. Online unter: www.gespraechsforschung-ozs.de/heft2000/ga-deppermann.pdf (Stand: 24.5.2018). S. $96-124$.

Deppermann, Arnulf (2005): Was sprichst du? Mischungen und Stilisierungen von Sprachen und Identitäten in Zeiten von Migration und globaler Popkultur. In: Neumann-Braun, Klaus/Richard, Birgit (Hg.): Coolhunters. Jugendkulturen zwischen Medien und Markt. Frankfurt a.M.: Suhrkamp. S. 67-82.

Dirim, İnci/Auer, Peter (2004): Türkisch sprechen nicht nur die Türken. Über die Unschärfebeziehung zwischen Sprache und Ethnie in Deutschland. Berlin/Boston: De Gruyter. (= Linguistik - Impulse und Tendenzen 4). 
Ehlers, Klaas-Hinrich (2013): Führte die Immigration der Heimatvertriebenen nach 1945 zu Dialektverlust und Nivellierung regionalsprachlicher Differenzen? Beobachtungen aus einer Untersuchungsregion in Mecklenburg. In: Niederdeutsches Jahrbuch 136. S. 97-116.

Ehlers, Klaas-Hinrich (2015): Vertriebenen-Linguistik. Geschichte und Profil der germanistischen Forschung zu den sprachlichen Folgen der Vertreibung nach dem Zweiten Weltkrieg. In: Hassler, Gerda (Hg.): Metasprachliche Reflexion und Diskontinuität. Wendepunkte - Krisenzeiten - Umbrüche. Münster: Nodus. S. 208-221.

Eichinger, Ludwig M./Plewnia, Albrecht/Steinle, Melanie (Hg.) (2011): Sprache und Integration. Über Mehrsprachigkeit und Migration. Tübingen: Narr. (= Studien zur Deutschen Sprache 57).

Fix, Ulla (2010): Sprachbiographien als Zeugnisse von Sprachgebrauch und Sprachgebrauchsgeschichte. In: Zeitschrift für Literaturwissenschaft und Linguistik 160. S. 10-28.

Franceschini, Rita (2002): Sprachbiographien. Erzählungen über Mehrsprachigkeit und deren Erkenntnisinteresse für die Spracherwerbsforschung und die Neurobiologie der Mehrsprachigkeit. In: Adamzik/Roos (Hg.). S. 19-33.

Füglein, Rosemarie (2000): Kanak Sprak. Eine ethnolinguistische Untersuchung eines Sprachphänomens in Deutschland. Diplomarbeit, Fakultät für Sprach- und Literaturwissenschaften der Otto-Friedrich-Universität Bamberg [unveröffentlicht].

Fürstenau, Sara/Gogolin, Ingrid/Yağmur, Kutlay (Hg.) (2003): Mehrsprachigkeit in Hamburg. Ergebnisse einer Sprachenerhebung an den Grundschulen in Hamburg. Münster u.a.: Waxmann.

Gogolin, Ingrid (1994): Der monolinguale Habitus der multilingualen Schule. Münster u.a.: Waxmann. (= Internationale Hochschulschriften 101).

Gumperz, John/Hymes, Dell (Hg.) (1972): Directions in sociolinguistics: the ethnography of communication. New York: Holt.

Haug, Sonja/Zerger Fritjhof (2006): Integrationskurse. Erste Erfahrungen und Erkenntnisse einer Teilnehmerbefragung. BAMF Abschlussbericht. (= Working Papers 5). Online unter: www.bamf.de/Shared Docs/Anlagen/DE/Publikationen/WorkingPapers/wp05-Integrationskurse.pdf?_blob=publicationFile (Stand: 16.2.2018).

Heidelberger Forschungsgruppe Pidgin (Hg.) (1975): Sprache und Kommunikation ausländischer Arbeiter: Analysen, Berichte, Materialien. Kronberg i.Ts: Scriptor Verlag.

Herbert, Ulrich (2001). Geschichte der Ausländerpolitik in Deutschland. Saisonarbeiter, Zwangsarbeiter, Gastarbeiter, Flüchtlinge. München: Beck.

Hinnenkamp, Volker (2005): „Zwei zu ,bir miydi“?“. Mischsprachliche Varietäten von Migrantenjugendlichen im Hybriditätdiskurs. In: Hinnenkamp, Volker/Meng, Katharina (Hg.): Sprachgrenzen überspringen. Sprachliche Hybridität und polykulturelles Selbstverständnis. Tübingen: Narr. S. 51-103. (= Studien zur Deutschen Sprache 32).

Human Rights Watch (1996): The Silenced Kurds. Bd. 8, 4 (E): The Middle East and North Arica. Online unter: www.hrw.org/reports/1996/Syria.htm (Stand: 28.2.2018).

Hymes, Dell (1962): The Ethnography of Speaking. In: Gladwin, Thomas/Sturtevant, William C. (Hg.): Anthropology and human behavior. Washington D.C.: Anthropological Society of Washington D.C. S. 13-53.

Keim, Inken (1978): Gastarbeiterdeutsch. Untersuchungen zum sprachlichen Verhalten türkischer Gastarbeiter. Tübingen: Narr. (= Forschungsberichte des Instituts für Deutsche Sprache 41).

Keim, Inken (2007): Die „türkischen Powergirls“. Lebenswelt und kommunikativer Stil einer Migrantinnengruppe in Mannheim. Tübingen: Narr. (= Studien zur Deutschen Sprache 39).

Klein, Wolfgang/Dittmar, Norbert (1979): Developing grammars. The acquisition of German syntax by foreign workers. Berlin: Springer.

Krumm, Hans-Jürgen (2001): Kinder und ihre Sprachen. Lebendige Mehrsprachigkeit. Sprachenporträts. Wien: Eviva. 
Meisel, Jürgen M. (2007). Mehrsprachigkeit in der frühen Kindheit. Zur Rolle des Alters bei Erwerbsbeginn. In: Anstatt, Tanja (Hg.): Mehrsprachigkeit bei Kindern und Erwachsenen. Erwerb, Formen, Förderung. Tübingen: Attempto. S. 93-114.

Meyer-Ingwersen, Johannes/Neumann, Rosemarie/Kummer, Matthias (1977): Zur Sprachentwicklung türkischer Schüler in der Bundesrepublik. Regensburg: Scriptor.

Orlović-Schwarzwald, Marija (1978): Zum Gastarbeiterdeutsch jugoslawischer Arbeiter im Rhein-MainGebiet: empirische Untersuchungen zur Morphologie und zum ungesteuerten Erwerb des Deutschen durch Erwachsene. Wiesbaden: Steiner. (= Mainzer Studien zur Sprach- und Volksforschung 2).

Pfaff, Carol W. (1984): On input and residual L1 transfer effects in Turkish and Greek children's German. In: Roger Andersen (Hg.): Second languages: a cross-linguistic perspective. Rowley u.a.: Newbury House. S. 271-298.

Scheible, Jana/Rother, Nina (2017): Schnell und erfolgreich Deutsch lernen - wie geht das? Erkenntnisse zu den Determinanten des Zweitspracherwerbs unter besonderer Berücksichtigung von Geflüchteten. (= Working Papers 72). Nürnberg: Bundesamt für Migration und Flüchtlinge. Online unter: www.bamf. de/SharedDocs/Anlagen/DE/Publikationen/WorkingPapers/wp72-erfolgreich-deutsch-lernen-wie.pdf? blob=publicationFile (Stand: 7.6.2018).

Schroeder, Christoph/Zakharova, Natalia (2015): Sind die Integrationskurse ein Erfolgsmodell? Kritische Bilanz und Ausblick. In: Zeitschrift für Ausländerrecht und Ausländerpolitik (ZAR) 8. S. 257-262.

Schuller, Karin/Lochner, Susanne/Rother, Nina (2011): Das Integrationspanel. Ergebnisse einer Längsschnittstudie zur Nachhaltigkeit und Wirksamkeit von Integrationskursen. (= Forschungsbericht 11). Nürnberg: Bundesamt für Migration und Flüchtlinge. Online unter: www.bamf.de/SharedDocs/Anlagen/DE/Publi kationen/Forschungsberichte/fb11-integrationspanel.pdf?_blob=publicationFile (Stand: 16.2.2018).

Stevenson, Patrick (2013): Sprachgeschichten mit Migrationshintergrund: demografische und biografische Perspektiven auf Sprachkenntnisse und Spracherleben. In: Deppermann, Arnulf (Hg.): Das Deutsch der Migranten. Berlin: De Gruyter. S. 9-40. (= Jahrbuch des Instituts für Deutsche Sprache 2012).

Stölting, Wilfried (1980): Die Zweisprachigkeit jugoslawischer Schüler in der Bundesrepublik Deutschland. Wiesbaden: Harrasowitz.

Thüne, Eva-Maria/Betten, Anne (Hg.) (2011): Sprache und Migration. Linguistische Fallstudien. Rom: Aracne. (= Lavori interculturali sul tedesco 4).

Tophinke, Doris (2002): Lebensgeschichte und Sprache. Zum Konzept der Sprachbiographie aus linguistischer Sicht. In: Adamzik/Roos (Hg.). S. 1-14.

Vertovec, Steven (2007): Super-diversity and its implications. In: Ethnic and racial studies 30, 6. S. $1024-1054$.

Wiater, Werner/Videsott, Gerda (2009): Migration und Mehrsprachigkeit. Frankfurt a.M.: Lang.

Wiese, Heike (2009): Grammatical innovation in multiethnic urban europe. New linguistic practices among adolescents. In: Lingua, 119. S. 782-806.

Wiese, Heike (2012): Kiezdeutsch. Ein neuer Dialekt entsteht. 2. durchges. Aufl. München: Beck.

David Hünlich, PhD/Dr. Sascha Wolfer/Dr. Christian Lang

Institut für Deutsche Sprache

R 5, 6-13

68161 Mannheim

E-Mail: huenlich@ids-mannheim.de/wolfer@ids-mannheim.de/lang@iids-mannheim.de 